\title{
In and Out of Balance: Industry Relatedness, Learning Capabilities and Post-Acquisition Innovative Performance.
}

\author{
Elena Cefis \\ Department of Management, Economics and Quantitative Methods, University of Bergamo, \\ Italy, and \\ Sant'Anna School of Advanced Studies, Pisa, Italy \\ elena.cefis@unibg.it \\ Orietta Marsili ${ }^{1}$ \\ School of Management, University of Bath, Bath BA2 7AY, U.K. \\ o.marsili@bath.ac.uk \\ Damiana Rigamonti \\ Department of Economics and Business Economics, Aarhus University \\ Århus, Denmark \\ damiana.rigamonti@gmail.com
}

This version: 25 February 2019

\begin{abstract}
Acknowledgments:
We thank the JMS editors and three anonymous reviewers for their helpful comments and excellent guidance. We are also grateful to Oliver Alexy, Panos Desyllas, Keld Laursen, Larissa Rabbiosi, Thomas Rønde, and participants in the AoM, DRUID, ENEF, EURAM and SIEPI conferences, and seminars at the universities of Aarhus, Bergamo, Piacenza, and Rotterdam, for valuable feedback on earlier versions of this manuscript. The empirical part of this research was carried out at Microdata - Centraal Bureau voor Statistiek (CBS), the Netherlands. The views expressed in this paper are those of the authors and do not necessarily reflect the policies of Statistics Netherlands. Elena Cefis acknowledges financial support from the University of Bergamo (grants ex 60\%, n. 60CEFI17 and n. 60CEFI18, Dept. of Management, Economics, and Quantitative Methods).
\end{abstract}

\begin{abstract}
The existence of an inverted $\mathrm{U}$-shaped effect of the relatedness between acquirer and acquired firm on the innovative performance subsequent to an acquisition is normally regarded as indicative of the existence of a trade-off between exploration and exploitation in external innovation search. We argue that acquirers endowed with heterogeneous learning capabilities can alter the shape of the trade-off to their favor. In particular, we focus on a notion of industry relatedness that captures the coherence between the domains of operation of the acquirer and the acquired firm. Using a longitudinal dataset of 1,736 domestic acquisitions in the Netherlands, we show that the heterogeneous learning capabilities of the acquirers alter the shape of the inverted-U relationship, according to first- and
\end{abstract}

\footnotetext{
${ }^{1}$ Corresponding author
}

This article has been accepted for publication and undergone full peer review but has not been through the copyediting, typesetting, pagination and proofreading process, which may lead to differences between this version and the Version of Record. Please cite this article as doi: $10.1111 /$ joms. 12441

This article is protected by copyright. All rights reserved. 
second-order moderating effects. Our results confirm that learning capabilities by internal R\&D and by acquisition experience both improve what acquirers can achieve in innovative performance when industry relatedness is at the point of balance between exploration and exploitation. In contrast, they have opposite implications on the potential losses in innovative performance when industry relatedness is outside the point of balance: internal R\&D increases the tolerance of the trade-off, smoothing out potential innovation losses, whereas acquisition experience reduces it.

Keywords: Exploration and exploitation; Industry relatedness; Innovation; Learning capabilities; M\&A

\section{INTRODUCTION}

While the success of related vis-à-vis unrelated acquisitions is a core topic in the Merger \& Acquisition (M\&A) literature, little is known about under which conditions related and unrelated acquisitions can lead to success in post-acquisition innovative performance. Adopting a learning capabilities approach (Levitt and March, 1988; Zollo and Winter, 2002), we define these conditions in terms of the interaction between industry relatedness and the heterogeneous learning capabilities of the acquiring firms, due to investments in $R \& D$ and acquisition experience, and we examine their effects on post-acquisition innovative performance. Prior research focuses on the effect of technological relatedness in the context of technology acquisitions, and finds that the effect is curvilinear, inverted U-shaped, when considering the impact on patented inventions (Ahuja and Katila, 2001; Cloodt et al., 2006; Sears and Hoetker, 2014) and market value (Grimpe and Hussinger, 2014) following an acquisition. This evidence is interpreted as indicative of the existence of a trade-off between the "exploration of new possibilities and the exploitation of old certainties" (March, 1991, p. 71), for firms pursing acquisitions as part of their explorative and exploitative search (Phene et al., 2012; Van Deusen and Mueller, 1999). Related acquisitions reflect concerns for improvement, integration and efficiency (Capron and Mitchell, 2004; Ranft and Lord, 2002), which are associated with exploitation (March, 1991). Unrelated acquisitions display characteristics of novelty, variation, and uncertainty (Barney, 1988; Graebner et al., 2010;

This article is protected by copyright. All rights reserved. 
Granstrand and Sjölander, 1990), which are associated with exploration (March, 1991). This curvilinear relationship sets the boundaries within which acquirers seek to balance exploration and exploitation in resource configuration (Greve, 2007). From a capability perspective (Bos et al. 2017; Kaul and Wu 2016), however, it is important to understand how these boundaries can be modified by the acquiring firms because of their own specific ability to benefit from a certain resource configuration pattern, and to translate such configuration into superior innovative performance (Prabhu et al., 2005; Zollo and Singh, 2004).

To fill this gap, we propose that the heterogeneous learning capabilities of the acquirers alter the shape of the inverted-U relationship, according to first- and second-order moderating effects. In particular, we account for two kinds of capabilities: in active learning (or learning by search) as the outcome of in-house R\&D, and in passive learning (or learning by doing) as the outcome of acquisition experience (Levitt and March, 1988; Zollo and Winter, 2002). By using data on 1,736 Dutch domestic acquisitions, we show that capabilities in active and passive learning help acquirers to shift the coordinates of the point of balance between exploration and exploitation to their favor, enhancing the innovative performance attainable at the optimal industry relatedness (first-order effect on the vertex of the invertedU). We also find that capabilities in active and passive learning have opposite effects on the tolerance of the trade-off, as they decrease and increase, respectively, the size of potential losses in innovative performance outside the optimal level of industry relatedness (secondorder effect on the focal length of the inverted-U).

By illustrating these moderating effects, we contribute to the understanding of the conditions that shape the relationship between relatedness, capabilities and post-acquisition innovative performance. Moreover, we investigate this relationship in a broader context than earlier studies. In prior M\&A research, relatedness is defined in terms of proximity between the contents of the knowledge basis of the acquirer and the acquired firm, as technological 
relatedness (Ahuja and Katila, 2001; Cloodt et al., 2006; Kapoor and Lim, 2007; Makri et al., 2010; Prabhu et al., 2005; Sears and Hoetker, 2014), or between the domains of products and markets, as industry or market relatedness (Makri et al. 2010). Proximity is measured along a pre-assigned hierarchical system of classification of technologies or sectors (Silverman, 1999). Conversely, in our study, we measure the degree of relatedness by applying Bryce and Winter's (2009) definition of a general index of industry relatedness, to M\&As. This index is based on the notion of coherence (Teece et al., 1994), as an expression of the fact that the resources basket of one industry matters also in another industry, without having to specify the nature of the resource differences. Hence, our index reveals whether an acquisition combines coherent domains of activity, regardless of the proximity between the technological knowledge and/or markets involved.

Furthermore, earlier studies consider the effect of technological relatedness on the patenting activity of acquiring firms in high-tech sectors, in which acquisitions are likely to be motivated by access to technological knowledge (Ahuja and Katila, 2001; Cloodt et al., 2006; Sears and Hoetker, 2014). Patented inventions are, however, intermediate output and imperfect indicators of innovative activities (Pavitt, 1985). In contrast, we consider the direct impact of industry relatedness on the sales revenues from innovation, recording innovative performance at the end of the entire commercialization process. Our approach allows to capture acquisition synergies that originate from access to complementary assets along the vertical chain (Puranam et al., 2006) and from diversification in product markets (Cassiman et al., 2005), all affecting commercialization (Teece, 1986). In this broader sense, acquisition synergies can influence innovation across a wider set of industries, including those with a low propensity to patent.

This article is protected by copyright. All rights reserved. 


\section{THEORETICAL FRAMEWORK}

\section{Exploration, exploitation and the inverted U-shaped relationship}

The critical source of value creation in acquisitions lays in the opportunity to create synergies between the parties (Larsson and Finkelstein, 1999); these synergies can be achieved in both related and unrelated acquisitions (Seth, 1990). Relatedness increases the integration potential' of an acquisition (Larsson and Finkelstein, 1999). Related acquisitions facilitate the transfer of resources of one company to another, which is necessary to realize 'efficiency synergies' through the exploitation of economies of scale and scope in the merged organization (Harrison et al., 1991). As for innovation outcomes, efficiency synergies originate from both technological and market relatedness (Cassiman et al., 2005). Technologically related acquisitions, in which the parties share similar and complementary knowledge bases, produce economies of scale and scope in the R\&D process, through operational improvements and elimination of duplicated efforts (Cloodt et al., 2006; Hagedoorn and Duysters, 2002; Makri et al., 2010). Market related acquisitions can generate both economies of scale in the production and distribution of innovative products (Cassiman et al., 2005), and economies of scope in $R \& D$ and in other activities, such as marketing and production, which are functional to the commercialization of innovation (Larsson and Finkelstein, 1999).

Conversely, un-relatedness increases the 'novelty potential' of an acquisition. Unrelated acquisitions generate 'unique synergies' through the recombination of resources profiles that are distant and idiosyncratic; their benefits are specific to the companies involved or are known only to few companies (Harrison et al., 1991). Hence, they have the potential to create resource configurations that are "uniquely valuable" (Barney, 1988) and to generate path-breaking change in the acquiring firm (Karim and Mitchell, 2000). Specifically, acquisitions in unrelated technological domains, by giving rapid access to novel ideas and

This article is protected by copyright. All rights reserved. 
knowledge, help acquirers build their own innovative capabilities (Arora and Gambardella, 1990; Graebner et al., 2010). Acquisitions in unrelated product markets give control over unfamiliar environments, reducing risks and uncertainty for the acquirer firms (Hagedoorn and Duysters, 2002). Furthermore, they can provide access to unique co-specialized complementary assets that buyers necessitate for commercializing their own innovations (Teece, 1986). Similarly, they can offer novel products to complement the buyer's own assets, and enable expanding the application and use of the buyer's own resources to innovations introduced elsewhere (Puranam et al., 2006).

In sum, the M\&A literature suggests that acquisitions contribute to innovation performance through two mechanisms, each one displaying an opposite association with the degree of relatedness in resources configurations between the parties involved: (a) relatedness increases the 'integration potential' of acquisitions and enhances the scope for exploiting efficiency synergies in the innovation process; (b) relatedness decreases the "novelty potential' of acquisitions and diminishes the scope for exploring unique synergies in the innovation process. ${ }^{1}$ As Haans et al. (2015) point out, this type of framework is a necessary condition to generate an inverted-U, when the two latent mechanisms are combined either additively or multiplicatively. Extant empirical evidence supports that there is an inverted-U relationship in the context of technology acquisitions and of the patenting activities of firms. Following a replication logic (Bettis et al., 2014), we test for this curvilinear relationship in a broader context, by using Bryce and Winter's (2009) general index of industry relatedness, across a wide range of industrial sectors.

This article is protected by copyright. All rights reserved. 


\section{The moderating effects of learning capabilities}

In Bryce and Winter's (2009) definition, applied to M\&As, industry relatedness is a structural property of the configuration of resources that characterizes the industries in which the acquirer and the acquired firm are active. By definition, this is a property specific to the combination or pair of industries that are connected in an acquisition. It reflects to what extent resources relevant for activities in the industry of the acquired firm are also relevant in the industry of the acquirer. Given this industries-specific property of an acquisition deal, we explain individual deal-level differences in innovative performance drawing on organizational learning theory, based on the heterogeneous learning capabilities of the acquiring firms. In particular, we account for the distinction between capabilities in 'active' and 'passive' learning (Zollo and Winter, 2002). Acquisitions can be part of the process of 'active learning' or 'learning by search' of firms that deliberately search and accumulate new knowledge from various sources both internally and externally to them (Dosi, 1982; Nelson and Winter, 1982). The rate of active learning depends on the rate of search (Levitt and March, 1988), which is influenced by the firm's own investments in R\&D (Nelson and Winter, 1982). Acquisitions also involve a process of 'passive learning' or 'learning by direct experience' (Levitt and March, 1988), because acquirers accumulate expertise through the repetition of 'making an acquisition'. Here, the rate of learning is a function of the experience built in performing a focal task and solving problems related to it (Levitt and March, 1988), that is, of acquisition experience (Barkema and Schijven, 2008).

Based on the above considerations, we focus on two acquirer-specific characteristics as moderators of the effect of industry relatedness on post-acquisition performance: the size of R\&D investments and acquisition experience. In particular, we distinguish first- and secondorder moderating effects on the inverted U-shaped relationship, modeled analytically by a parabola. The first-order moderating effect comprises a shift in the position of the inverted-U 
without changing its shape. By this effect, the level of industry relatedness that maximizes innovative performance, as identified by the vertex of the parabola, changes. This represents a variation in the coordinates of the point of balance in the trade-off between exploration and exploration. The second-order effect consists of a change in the shape of the inverted-U, as the curvature of the parabola becomes flatter or steeper. By this effect, the size of the potential losses in innovative performance, which are consequent to departing from the optimal (maximizing) level of industry relatedness, changes. This represents a variation in the tolerance of the trade-off between exploration and exploitation to possible departures from the point of balance.

\section{Acquirer's in-house R\&D investments}

In-house $\mathrm{R} \& \mathrm{D}$ activities contribute to the knowledge basis firms draw upon in their process of active learning, and create a pool of opportunities for innovation internally to the organization (Levitt and March, 1988; Nelson and Winter, 1982). In this process, pairing internal search with external search enables firms to benefit from complementarities and synergies in resources and capabilities, which enhance innovative performance (Cassiman and Veugelers, 2006). By investing in internal R\&D firms develop a basis of prior knowledge and problem-solving skills, which increase their 'absorptive capacity': their ability to recognize the value of knowledge produced elsewhere and to effectively assimilate and apply it (Cohen and Levinthal, 1989, p. 128). A greater absorptive capacity increases the returns from an internal search in the presence of external search, and vice versa (Cassiman and Veugelers, 2006, p. 76). Based on the absorptive capacity argument, earlier studies conclude that a larger size of the knowledge basis prior to an acquisition positively influence innovative performance post-acquisition (Ahuja and Katila, 2001; Cloodt et al., 2006). ${ }^{2}$ Besides this direct effect on post-acquisition innovative performance, we propose that $R \& D$

This article is protected by copyright. All rights reserved. 
expenditures also moderate the effect of industry relatedness. Larger R\&D investments imply a larger and richer, more diversified, pool of knowledge and expertise within the company (Levitt and March, 1988; Nelson and Winter, 1982). Therefore, acquirers investing more in $\mathrm{R} \& \mathrm{D}$ are more likely to own prior knowledge that can assess and exploit outside resources relevant in industry domains normally unrelated to the industry in which the acquirers are active. Hence, R\&D investments enhance the integration potential of an acquisition. As emphasized (Haans et al., 2015), to have an inverted-U effect it is not sufficient that the independent variable exerts both positive and negative effects. It is also necessary that the positive effect is greater than the negative effect when the independent variable is low, and vice versa when the independent variable is high. In our framework, this condition implies that the integration effect (a) is dominant over the novelty effect (b) when industry relatedness is low. This assumption is consistent with the notion in the M\&A literature that, in a situation of over-exploration (too low relatedness), the gains in integration potential from increasing relatedness outbalance the marginal losses due to reduced novelty (Capron and Mitchell, 2004; Van Den Bosch et al., 1999). As a consequence, the enhanced integration potential of acquisitions carried out by acquirers investing in $R \& D$ is more impactful at low levels of industry relatedness (below the optimum). Hence, R\&D-investing acquirers are in a better position to exploit industry-unrelated acquisitions of higher novelty potential. We characterize this as a first-order moderating effect: larger $R \& D$ investments enable the acquiring firm to achieve a higher (maximum) level of post-acquisition innovative performance at a lower (optimal) level of industry relatedness. This effect translates into a shift of the coordinates of the point of balance between exploration and exploitation (i.e. the vertex of the inverted-U curve) towards lower industry relatedness and higher innovative performance.

This article is protected by copyright. All rights reserved. 
HYPOTHESIS 1a: The acquirer's prior $R \& D$ expenditure moderates the inverted- $U$ relationship between industry relatedness and post-acquisition innovative performance, by shifting the point of balance towards lower industry relatedness, and higher innovative performance.

When acquirers fail to choose an acquisition target from one optimally related industry, they face losses regarding the outcomes they could have achieved post-acquisition had they made the optimal choice, because of either over-exploitation or over-exploration. R\&D expenditures can help to mitigate such losses. By investing in $R \& D$, firms engage in a process of internal search characterized by longitudinal uncertainty, largely driven by experimentation and trial-and-error learning, with partly random outcomes (Dosi, 1988). Accordingly, larger R\&D investments are likely to produce greater variance in the search outcomes, and in the range of possible resources combinations and potential uses of these resources (Nelson and Winter, 1982). Thus, with over-exploration, acquirers with larger R\&D investments can rely on a greater 'combinatorial potential' of their resources basis (Ahuja and Katila, 2001). Furthermore, R\&D activities produce 'discovery efficiencies'. Because of experimentation and trial-and-error learning, R\&D active firms discover new resources, which introduce new resource combinations and reveal further resource uses $(\mathrm{Ng}$, 2007). Hence, firms can rely on a greater variety of options for finding productive combinations and uses of 'excessively' unrelated resources. To the other end, with overexploitation, R\&D active acquirers can compensate the costs of excessive resources overlap because their innovative efforts can benefit from greater market power, through resources aggregation, and from spreading R\&D costs across a larger volume of activity (Cassiman et al., 2005). Based on these arguments, we assume that R\&D investments lower the potential losses in post-acquisition innovative performance of not selecting the optimal level of

This article is protected by copyright. All rights reserved. 
industry relatedness. This second-order moderating effect of $R \& D$ investments entails greater tolerance in the trade-off between exploration and exploitation to departures from the point of balance; the effect is represented by a flatter curvature of the inverted-U.

HYPOTHESIS 1b: The acquirer's prior $R \& D$ expenditure moderates the inverted- $U$ relationship between industry relatedness and post-acquisition innovative performance by reducing the impact on innovative performance of deviations from the optimal level of industry relatedness.

\section{Acquisition experience}

The effect of acquisition experience on post-acquisition performance has been widely studied in the M\&A literature, with a focus on financial performance, and mixed results (Barkema and Schijven, 2008). Some observe that while experience and learning-by-doing can positively affect post-acquisition performance through a faster and smoother acquisition integration process (Hitt et al., 1998), experience can also create negative transfer effects when old knowledge applies to new domains (Haleblian and Finkelstein, 1999). The main conclusion from the extant literature is that a direct effect of acquisition experience is likely to be not significant, instead, the effect is nonlinear (U-shaped), dynamic, and contingent to the domain of application (Barkema and Schijven, 2008). Accordingly, firms go through an incremental learning path: early in the learning curve, little (but not too much) experience facilitates learning in related domains. Then, over time and after successive acquisitions firms build a large enough and diversified experience pool that enables effective learning in unrelated domains (Barkema and Schijven, 2008; Haleblian and Finkelstein, 1999). The existence of an inverted U-shaped relationship implies, as a necessary condition, that the integration effect (a) is dominant over the novelty effect (b) when industry relatedness is low.

This article is protected by copyright. All rights reserved. 
Hence, the moderating effect of experience, increasing integration potential, will be most relevant for innovation when industry relatedness is low, while it will be marginal when industry relatedness is high. We can then conclude that the innovation outcomes of acquisitions improve when firms draw on a sufficiently large pool of experience to facilitate the integration process of resources from unrelated domains, of greater novelty potential. Hence, the first-order moderating effect of acquisition experience is to increase postacquisition innovative performance from unrelated industry domains. This effect leads to a shift of the coordinates of the point of balance between exploration and exploitation towards lower industry relatedness and higher post-acquisition innovative performance.

HYPOTHESIS 2a: Acquirer's M\&A experience moderates the inverted-U relationship between industry relatedness and post-acquisition innovative performance, by shifting the point of balance towards lower industry relatedness and higher innovative performance.

As for the second-order moderating effect, and contrary to the assumption made for $\mathrm{R} \& \mathrm{D}$, we argue that acquisition experience can accentuate the potential losses in postacquisition innovative performance, when acquisitions do not fulfill the optimal level of industry relatedness. Active learning and passive learning generate different types of capabilities to adapt and change, which Ng (2007) differentiates as 'strong' and 'weak' dynamic capabilities. Learning by experience, or passive learning, enhances the capability to solve problems connected to a specific task. By repeating the task, firms accumulate experience about how to use their resources to carry out the task more proficiently and effectively; they accumulate 'resource use experience'( $\mathrm{Ng}, 2007)$. Resource use experience in 'how to make an acquisition' generates acquisition capabilities, which are stored and retained by the firms in both undeliberate and deliberate forms, through the development of routines,

This article is protected by copyright. All rights reserved. 
the codification of knowledge in manuals, systems and tools, and the establishment of dedicated acquisition units (Zollo and Singh, 2004). Furthermore, in passive learning, experience and 'problemistic search' (Cyert and March, 1963) lead to the discovery of new uses to existing resources, which are closely related to the firm's prior experience of resource use (Ng, 2007). In contrast, in active learning, experimentation and 'combinatorial search' (Fleming and Sorenson, 2004) lead to the discovery of new resources, which reveal further new uses. Thus, experience reinforce existing practices and routines that were developed based on prior successes and failures, creating path-dependency and possible bias towards solutions that already proved to be successful (Levitt and March, 1988; Zahra and George, 2002). Because of the emphasis on current strengths and routine development, experience favors exploitation over-exploration (Greve, 2007). Thus, while active learning expands the search space, passive learning may limit it. Consistent with this argument, Hayward (2002) observes that learning by experience is most effective when newly acquired resources are optimally related, neither too similar nor too dissimilar, to prior acquisitions (itself an inverted U-shaped effect). In summary, we conclude that by constraining the capabilities of acquirers to adapt and change, in response to situations in which the resources profiles are not optimally configured, acquisition experience leads to greater potential losses outside the point of balance between exploration and exploitation. Hence, the second-order moderating effect of experience is to lower the tolerance of the trade-off; the curvature of the inverted-U becomes narrower.

HYPOTHESIS 2b: Acquirer's M\&A experience moderates the inverted-U relationship between industry relatedness and post-acquisition innovative performance, by increasing the impact on innovative performance of deviations from the optimal level of industry relatedness.

This article is protected by copyright. All rights reserved. 


\section{METHODS}

\section{Data sources}

We use data from the Netherlands General Business Register (ABR) ${ }^{3}$ and the Community Innovation Surveys (CIS) on firms operating in the Netherlands. Both datasets are managed by the Netherlands Central Bureau of Statistics (CBS). The ABR contains data at the level of the business legal unit for the population of firms registered for fiscal purposes in the Netherlands and includes economic and demographic information. The CIS is a European Union (EU) survey aimed at gathering harmonized data on the innovative activities and performance of firms, carried out by the member Nations under Eurostat coordination. CIS data and the derived indicators of innovation activities and performance have been used extensively in studies on the economics and management of innovation (Cassiman and Veugelers, 2002; Cassiman and Veugelers, 2006; Klingebiel and Rammer, 2014; Laursen and Salter, 2006; Leiponen and Helfat, 2010; Love and Roper, 2002; Mairesse and Mohnen, 2002). The Dutch CIS is conducted every two years; each wave covers the three-year period before the survey year. Seven CIS waves, from 1994 to 2008, were available for this study: CIS 2 (1994-1996), CIS2.5 (1996-1998), CIS3 (1998-2000), CIS3.5 (2000-2002), CIS4 (2002-2004), CIS 4.5 (2004-2006), and CIS 5 (2006-2008). The CIS is administered by the CBS to a random sample of firms extracted from those registered in the ABR (firms' population), and stratified according to firm size, region, and industry. The CIS samples are designed to reduce biases and distortions in the representation of the firms' population.

\section{Sample}

For the construction of our sample we first identified in the ABR all M\&A deals, 29,388, that took place in the Dutch market over the period 1997-2005. Second, from the same ABR data, we collected, for each M\&A deal, information on the age, size, and sector of activity of the 
acquirer and the acquired firm at the date of the acquisition, as observed in the ABR. Third, we matched the above demographic data from the ABR with firm-level innovation data from the CIS using the firms' identification code provided internally by the Statistical Office, as follows. First, for each acquiring firm, we gathered the data on 'pre-acquisition' innovative activities from the CIS wave immediately before the date of the acquisition. Second, for the same acquiring firm, we added data on the 'post-acquisition' innovative performance using the CIS wave that follows the year of acquisition. Neither the "prior" nor the "following" CIS waves include the acquisition year. In view of the timeline of the CIS waves, the postacquisition innovative performance is observed after an integration period ranging from 3 to 5 years. For instance, if the acquisition happened in 2005 (the last year in our sample), a typical data sequence would contain (i) demographic data (firm age, size and sector) extracted from the ABR in the year of acquisition, i.e. 2005; (ii) pre-acquisition innovative activities and performance data extracted from the CIS wave immediately preceding the acquisition, i.e. 2002-2004 and (iii) post-acquisition innovative performance data extracted from the CIS wave following the year of acquisition, i.e. 2006-2008. Each CIS wave provides the sales revenues from innovative products and services, as reported at the end of the $3^{\text {rd }}$ year of the wave. Hence, for the same example as above, the 'pre-acquisition' innovative performance (measured by innovative sales revenues) is calculated in the year 2004; the 'post-acquisition' innovative performance is calculated in 2008 , three years after the M\&A deal was concluded.

The outcome was a final sample of 1,736 domestic acquisition deals realized between 1997 and 2005 involving manufacturing, service, and construction firms. The reduction in the sample size from the initial number of M\&As is because not all the firms involved in M\&As, as identified in the population of registered firms (ABR), are included in the samples surveyed in the CIS. It is worth noting that our study takes into consideration only firms that 
actually perform an acquisition, given that our unit of observation is the acquisition deal; therefore, our results are not generalizable to the entire firms' population, but concern only those firms that engage in acquisitions.

\section{A model of moderating effects to a curvilinear relationship}

The existence of a curvilinear relationship between an indicator of performance and an index of relatedness is generally formalized using a parabolic function, such as:

$$
y=a x^{2}+b x+c
$$

The existence of an inverted-U is equivalent to the condition $a<0$. To test separately for first- and second-order moderating effects, we use the two analytical properties that fully identify the shape of the parabola: (i) the vertex, defining the position of the parabola on the $x y$-plane, with coordinates:

$$
V=\left(-\frac{b}{2 a},-\frac{b^{2}-4 a c}{4 a}\right)
$$

and (ii) the focal length, defining the center of the parabola, i.e. the distance between the vertex and the focus, measured on the axis of symmetry of the parabola. The focal length reflects how steep or flat is the curvature and is expressed as:

$$
f=\frac{1}{4|a|}
$$

where $|\mathrm{a}|$ is the absolute value of the coefficient $a$. High values of the coefficient $a$ imply low focal length and a steep curvature; low values of $a$ imply high focal length and a flat curvature.

This article is protected by copyright. All rights reserved. 
A first-order moderating effect of a variable $z$ on the curvilinear relationship can be introduced in the form of a variation in the linear coefficient of equation (1), with the new coefficient set to $(b+\delta z)$. This is equivalent to assuming that, if the value of $z$ changes, the vertex (and position) of the parabola shifts without changing its curvature, since the latter is determined by the focal length which is a function exclusively of the parameter $a$. Specifically, with an inverted-U in a model with only linear interaction terms, the parabola shifts towards the left-hand side if the coefficient of the interaction term is negative, i.e. $\delta<0$ (the $x$-coordinate decreases), and toward the right-hand side if it is positive, i.e. $\delta>0$ (the $x$ coordinate increases). Accordingly, Hypotheses $1 a$ and $2 a$, which entail a shift of the coordinates of the point of balance between exploration and exploitation towards lower industry relatedness, are equivalent to $\delta<0$ in a model with only linear interaction terms, which maintains the curvature of the inverted-U constant.

A second-order moderating effect to the curvilinear relationship consists in a change in the parabola's curvature, while holding the position of the vertex constant. We formulate this effect as a variation in the quadratic coefficient of equation (1), with the new coefficient set to $\left(a+\gamma z^{2}\right)$. This has the effect of changing the focal length, and the curvature of the parabola, according to equation (3). Under an inverted-U shape, an increase in the moderating variable $z$ will increase the focal length and flatten the curvature, if the coefficient of the quadratic interaction term is positive $(\gamma>0)$. Conversely, it will reduce the focal length and narrow the curvature if the coefficient is negative $(\gamma<0)$. Hence, Hypothesis $1 b$ of greater tolerance of the exploration-exploitation trade-off with R\&D activities is equal to $\gamma>0$. Hypothesis $2 b$ of lesser tolerance with acquisition experience, is equal to $\gamma<0$. The complete model is: ${ }^{4}$

$$
y=\left(a+\gamma Z^{2}\right) X^{2}+(b+\delta Z) X+\lambda S+e
$$

This article is protected by copyright. All rights reserved. 
where $X, Z$, and $S$ are the vectors of explanatory, moderating, and control variables, respectively.

\section{Empirical model}

We can observe innovative sales revenues only for firms that introduce new products or services. Estimating a standard regression model on the subset of firms for which we can measure innovative sales leads to the risk of sample selection bias. Specifically, in our setting, sample selection may emerge because of "incidental truncation" (Certo et al., 2016, p. 8; Wooldridge, 2010, p. 777) of our data. Incidental truncation occurs because we are able to observe our dependent variable, innovative sales revenues, only for firms that do introduce new or significantly improved products (and services) subsequent to an acquisition, while the value of the dependent variable is missing for those firms that do not introduce product innovations. In other words, the probability of inclusion of an acquisition deal (our unit of observation) in the estimation sample (i.e. the probability that the acquisition resulted in an innovation) is affected by unobservable variables. Idiosyncratic capabilities may influence the choice to engage in innovative activities and the ability to complete an innovation project, and therefore the probability to be included in the estimation sample, as well as the level of post-acquisition sales revenues from innovation.

To mitigate this problem, we apply a two-stage Heckman model (Heckman, 1979), widely used to control for sample selection bias in studies of innovation performance (Cassiman and Veugelers, 2006; Mairesse and Mohnen, 2002). Specifically, we apply the selection equation (Probit regression) of the first stage of the Heckman model to estimate the probability that an acquisition deal enters the sample on which we have predicted firms' innovation sales. Through this first stage, we obtain the inverse Mill's ratio $(\lambda)$, which is added to the performance equation of the second-stage (the OLS regression) of the Heckman 
correction procedure. The inverse Mill's ratio is a proxy of the sample selection effect because of unmeasured firm innovative capabilities, a component that otherwise would be omitted and leading to inconsistent estimators.

The 'exclusion restrictions' in the Heckman $1^{\text {st }}$ stage estimator require that at least one independent variable in the selection equation, modeling the probability that the acquisition resulted in product innovations, is unrelated (orthogonal) to the volume of sales realized from the innovation after the acquisition, which constitutes the dependent variable of the performance equation in the $2^{\text {nd }}$ stage of the Heckman model (Certo et al., 2016; Wooldridge, 2010). We use as exclusion restrictions the information from the CIS on the types of obstacles to innovation faced by firms (Cefis, 2010). The CIS asks all respondents to indicate whether they experienced obstacles that prevented innovative activities or projects from starting, of three kinds: (i) financial constraints, (ii) lack of qualified personnel and information about the technology, and (iii) lack of market information. Earlier studies based on CIS data show that the obstacles to innovation are 'perceived' by companies as constraints, but in fact do not discourage companies from innovating (Veugelers and Cassiman, 1999). Nevertheless, the perception of obstacles influences firms' decisions about their innovation strategies, such as the choice between producing a technology internally and sourcing it externally (Veugelers and Cassiman, 1999). Hence, the perception of obstacles to innovation is likely to influence the innovation strategy of the acquirer, and whether the acquisition will result in the introduction of new products. It is also reasonable to assume, however, that the perceived (rather than actual) obstacles to innovation are not direct determinants of the level of innovative sales revenues that acquirers can achieve following the acquisition; these revenues will depend on the capabilities necessary to successfully commercialize the innovation (Teece, 1986). To test the validity of our exclusion restrictions, we have estimated the full model (model 3 and $3 \mathrm{a}$ in Table IV) including the exclusion 
restrictions in the performance equation. The coefficients of these regressors, when controlling for the occurrence of a new product/service introduction, are statistically nonsignificant, thus supporting the assumption that the obstacles to innovation are largely orthogonal to post-acquisition innovative sales revenues. ${ }^{5}$

Differences among acquirers in the innovative sales revenues following an acquisition may originate unobservable heterogeneity, which produces systematic and persistent asymmetries in innovative performance. This leads to a problem of omitted variables in the error term of the regression model, and consequently to inconsistent estimators. Because past innovative performance is a major predictor of future innovative performance (Geroski et al., 1997) due to the cumulative nature of the innovation process (Dosi, 1988), one way to attenuate this problem and to control for firm-level fixed effects is to introduce an autoregressive component (Bettis et al., 2014). Hence, we add the lagged value of the dependent variable (i.e. the acquirers 'pre-acquisition' innovation sales in the CIS wave preceding the acquisition) to the right-hand side of the performance equation. Acquiring firms with superior idiosyncratic innovative capabilities are likely to perform persistently better than others, before and after the acquisition, as for example observed in the number of patents produced (Ahuja and Katila, 2001; Cloodt et al., 2006).

\section{Dependent variables}

In the first stage of the Heckman model, we model the probability for the acquiring firm to innovate after the acquisition, using as the dependent variable a dummy indicating whether the firm introduced new or significantly improved products/services. In the second stage, we model the post-acquisition innovative performance measured by the firm's sales originating from new and significantly improved products and services. As a sensitivity analysis, we also

This article is protected by copyright. All rights reserved. 
distinguish each innovation measure according to the degree of novelty, based on whether the products and services are (a) improved or new to the firm (but already available to competitors), or (b) new to the market. It should be noted that a firm can be an innovator according to the dummy variable definition while realizing innovative sales revenues equal to zero if the product has not yet achieved successful commercialization in the market. In all specifications, we use the total sales revenues from innovation, in logarithms, instead of the percentage on the total sales. The advantage is that sales revenues measure the overall extent of commercial success of the innovation (Leiponen and Helfat, 2011). As well, an increase in sales revenues can be attributed more directly to the innovative activities of the firm, while a relative increase in the percentage of innovative sales may be due to declining sales of other product offerings (Klingebiel and Rammer, 2014). From an econometric point of view, using total revenues offers more precise estimates because based on a continuous variable which, different from a percentage, is not affected by truncation.

\section{Independent variables}

Industry relatedness. Our measure of industry relatedness is adapted from the index proposed by Teece et al. (1994). We consider each acquisition event to identify the co-occurrence of the industry of the acquired firm, considered as the source of resource transfer, and the industry of the acquiring firm as its destination. We then calculate the relatedness index by comparing the number of co-occurrences across all acquisitions, $o_{i j}$, observed between the industry $(i)$ of the acquirer and the industry $(j)$ of the acquired firm, and the number that would have been expected in randomly occurring pairs. Thus, the relatedness index $\rho_{i j}$ is defined as: $\rho_{i j}=\left(o_{i j}-\mu_{i j}\right) / \sigma_{i j}$, where $\mu_{i j}$ and $\sigma_{i j}$ are the mean and standard deviation of randomly distributed pairs, which are best represented by a hypergeometric distribution (Teece et al., 1994). In the regression analysis, the index is calculated in natural logarithms 
after linear transformation to assume only positive values, according to the expression: Relat $_{i j}=\ln \left\{1+\left[\rho_{i j}+\left|\min \left(\rho_{i j}\right)\right|\right]\right\}$.

This index is particularly suited to representing relatedness in resource profiles (Bryce and Winter, 2009; Speckbacher et al., 2015). Because the index is calculated as the frequency of co-occurring industry codes across actual acquisitions, it reflects the existence of connections (or coherence) between the resource profiles of industries, irrespective of their distance in a pre-defined hierarchical ordering of industry codes. Furthermore, in our application, the index is unidirectional, since it accounts for the source and destination of the connection established with an acquisition. Hence, the degree of industry relatedness can vary between the acquirer-acquired pair of industries $(i, j)$ and the acquirer-acquired pair of industries $(j, i)$. We calculate the index on the populations of acquisitions completed in the Dutch market over the period 1980-2005 (36,375 deals), as identified through the ABR dataset. For the entire set of industries at 3-digit level of the NACE classification, we obtain $204 \times 204$ combinations of acquirer and acquired industries.

Moderating variables. The first moderating variable is the acquirer's R\&D internal spending. Cloodt et al. (2006) find a significant negative effect of $R \& D$ expenditures on the patenting output subsequent an acquisition, while the same effect is not statistically significant in the study by Ahuja and Katila (2001). Conversely, Makri et al. (2010) observe a significant positive effect of $R \& D$ intensity on the quality and quantity of patents following acquisition. In the CIS definition, the internal R\&D spending comprises all the expenditures related to R\&D performed by the firm's own personnel. It also includes the costs of acquisition of hardware/software and new machinery, market research aimed directly at the market introduction of new products or services, and R\&D personnel training. We draw this variable from the CIS wave before the acquisition year. It is then normalized and entered the empirical model as the percentage of the total volume of sales revenues, or $R \& D$ intensity

This article is protected by copyright. All rights reserved. 
(Makri et al., 2010). Because of companies who do not carry out R\&D and the skewness of the distribution, we add 1 and transform in logarithm. The second moderator is the acquirer's acquisition experience, which, from the ABR data, we can measure by the total number of acquisitions. Also this variable is transformed in logarithm. Makri et al. (2010) find a positive statistically significant effect of acquisition experience on invention quantity following an acquisition, while the effect is not significant for invention quality and novelty.

Control variables. In the analysis, we include several factors that can influence postacquisition innovative performance. Large and established firms use acquisitions of small and young firms as the means to acquire novel technologies and resources (Granstrand and Sjölander, 1990; Reuer and Ragozzino, 2008). Hence, to control for the relative size (Ahuja and Katila, 2001; Cloodt et al., 2006; Makri et al., 2010; Sears and Hoetker, 2014) and relative age of the parties involved, we include, for both the acquirer and the acquired firm, the number of employees (as a measure of firm size) and the number of years between the date of first registration of the firm into the ABR and the date of the acquisition (as a measure of firm age), in logarithms. Sectoral differences in the knowledge environment or technological regime in which acquirers and acquired firms operate (Breschi et al., 2000; Pavitt, 1984) can also affect post-acquisition innovative performance (Cloodt et al., 2006; Makri et al., 2010). To control for sectoral differences, we introduce dummy variables for the four categories of technological intensity defined by the Eurostat aggregation of industrial sectors at the 3-digit NACE level grouped as follows: i) high-tech and medium-high technology manufacturing; ii) low-tech and medium-low technology manufacturing; iii) knowledge-intensive services (KIS); iv) less knowledge-intensive services (LKIS). In the first stage of the Heckman model, we include only the attributes of the acquirer as control variables of the probability that the acquirer innovates post-acquisition. In the second stage, we consider the attributes of both the acquirer and the acquired firm as control variables of

This article is protected by copyright. All rights reserved. 
post-acquisition innovative sales. In all models, we include dummy variables per calendar year (Ahuja and Katila, 2001), from 1997 to 2004.

\section{RESULTS}

Table I presents the descriptive statistics and the Pearson's correlation $r$. The low values of $r$ between the independent variables, and the acceptable variance inflation factor (VIF) statistics suggest that multicollinearity is not a problem in our analysis. Table II describes the sample.

Table III reports the estimates of the probability that the acquiring firm introduces new or significantly improved products/services after the acquisition (the selection equation or $1^{\text {st }}$ stage), using as the dependent variable both indicators of post-acquisition innovation: new-tothe-firm innovation (model 1), and new-to-the-market innovation (model 2). For both indicators, the probability to innovate post-acquisition is higher for the acquirers that, before the acquisition, experienced obstacles to innovation in the form of lack of knowledge and market uncertainty but did not experience obstacles to innovation in the form of financial constraints.

The coefficients of the performance equation $\left(2^{\text {nd }}\right.$ stage $)$ are reported for the sales revenues of new-to-the-firm products (Table IV: model 1, 2 and 3) and of new-to-the-market products (Table IV: model 1a, 2a and 3a). Models 1 and 1a account only for the direct effects and include the square value of the industry relatedness index to test for the inverted-U shape of the curve, in a replication logic. As for the control variables, we find that post-acquisition innovative performance is positively influenced by the acquirer's size, and in the case of new-to-the-firm innovations, by the performance prior to the acquisition. In contrast, the 
autoregressive term is not statistically significant for new-to-the-market innovations, indicating that for products of greater novelty (Klingebiel and Rammer, 2014) revenues are less persistent and more unpredictable over time.

The coefficient of the square term of the relatedness index is negative and statistically significant, supporting the well-known inverted U-shaped curve, $a<0$ in equation (1). While the signs of the coefficients of relatedness and its square term are invariant across the model specifications, the absolute sizes are always higher for new-to-the-market innovation (model 1a) than for new-to-the-firm innovation (model 1). To assess the overall effect of these differences, Table $\mathrm{V}$ reports the vertex coordinates and focal length of the estimated parabola for models 1 and 1a on the first row. This shows that, for new-to-the-market innovations, the vertex of the parabola, with coordinates $(x=3.24, y=8.64)$, is positioned towards higher levels of sales revenues compared to the vertex of the parabola, with coordinates $(x=3.22, y=5.85)$, for new-to-the-firm innovations, at approximately the same level of industry relatedness. As for the focal length of the parabola, this is smaller for new-to-the-market innovation $(0.29)$ than for new-to-the-firm innovation (0.53). This suggests that while post-acquisition innovative performance at the optimal level of industry relatedness is higher for products of greater novelty, at the same time, losses in innovative performance when deviating from the optimal level of relatedness are also more significant (the curvature of the inverted-U is narrower). Thus, for greater novelty in product innovation, industry relatedness can more easily turn out to be too high or too low to achieve post-deal success. Conversely, for new-tothe-firm innovations, the level of post-acquisition innovative performance at the optimal level of industry relatedness is lower, but the outcome is less sensitive to deviations from the optimal level of relatedness (the curvature of the inverted-U is broader). Hence, the tolerance 
in industry relatedness for post-acquisition performance is higher for less novel product innovations.

To test for first- and second-order moderating effects of the acquirer's internal R\&D, we add the linear and quadratic interaction terms of the variable $R \& D$ intensity with the relatedness index, in the two model formulations, for new-to-the-firm innovation sales (model 2) and new-to-the-market innovation sales (model 2a). In both models, we observe that the estimated coefficient of the linear interaction term is negative and statistically significant, while the estimated coefficient of the quadratic interaction term is positive and statistically significant. Last, we add the interaction terms with acquisition experience, obtaining the complete models 3 for new-to-the-firm innovation sales, and 3a for new-to-the-market innovation sales. In both models, the coefficients of the interaction terms with $R \& D$ intensity remain largely invariant as compared to the previous estimates of models 2 and 2a. Overall, a variation in $R \& D$ expenditure has the effect of changing both the position of the curve (the vertex) and the shape of the curve (the focal length). To visualize these effects, we plot the performance-relatedness curve for high and low levels of the acquirer's R\&D expenditure, for new-to-the-firm (Figure 1a) and new-to-the-market innovation sales (Figure 1b). In both cases, the inverted-U curve shifts to the left hand-side for a higher level of the acquirer's $\mathrm{R} \& \mathrm{D}$ expenditure. This is also confirmed by the variations in the vertex coordinates, reported in Table $\mathrm{V}$ for the complete model (model 3 and $3 a){ }^{6}$ Specifically, for new-to-the-firm innovation sales, the vertex coordinates move from $(x=2.88, y=5.33)$ to $(x=1.64, y=5.56)$, towards higher values of innovative performance and lower industry relatedness, with increasing R\&D. For new-to-the-market innovation, the vertex coordinates shift from $(\mathrm{x}=3.24, \mathrm{y}=7.42)$ to $(\mathrm{x}=2.93, \mathrm{y}=7.36)$, towards marginally lower innovative performance, and lower industry relatedness. At the same time, due to the significance of the quadratic 
interaction term, the curvature of the parabola changes: the focal length increases from 1.48 to 2.30 for new-to-the-firm innovation and from 0.61 to 0.71 for new-to-the-market innovation. This implies that at higher levels of $R \& D$ expenditures the curvilinear relationship becomes flatter. Hence, acquirers investing in internal R\&D more intensively are able to balance exploration and exploitation in external search by acquisition at a lower level of industry relatedness, somewhat increasing post-acquisition innovative performance, overall consistent with Hypothesis 1a. In view of their internal R\&D, acquirers also benefit of greater tolerance should they fail to achieve such balance, supporting Hypothesis $1 \mathrm{~b}$.

As for the moderating effects of acquisition experience, the coefficient of the linear interaction term is positive and statistically significant, while the coefficient of the quadratic interaction terms is negative and statistically significant, in the complete Models 3 and $3 \mathrm{a}$ of Table IV. It is worth noting that in the complete model for new-to-the-firm innovation sales (model 3), the direct effect of industry relatedness and its square term are no longer statistically significant. These are the values of the parameters $a$ and $b$ in equation (4), and capture the (conditional) effects of $X$ and $X^{2}$ on $Y$ when the moderating variable $Z$ is equal to zero (Brambor et al., 2006). Their interpretation is different from the 'average' or unconditional effects of $X$ and $X^{2}$ on $Y$ in the model without interactions terms, i.e. $a$ and $b$ of equation (1), both statistically significant. In this case, these results indicate that the (conditional) effect of industry relatedness cannot be considered as an inverted U-shaped conditionally on R\&D and acquisition experience being both equal to zero, while it follows an inverted-U for positive values of the two moderators.

This article is protected by copyright. All rights reserved. 
As shown in Figure 2, for a higher level of acquisition experience, the parabola shifts towards the left hand-side, with the vertex moving towards a lower value of industry relatedness, and a higher maximum value of innovative performance. ${ }^{7}$ The vertex coordinates change from $(\mathrm{x}=4.51, \mathrm{y}=5.40)$ to $(\mathrm{x}=2.72, \mathrm{y}=6.70)$ for new-to-the-firm innovations, with increasing acquisition experience, and from $(\mathrm{x}=3.90, \mathrm{y}=7.23)$ to $(\mathrm{x}=2.81, \mathrm{y}=8.23)$ for new-tothe-market innovations (Table V). As for the focal length, this decreases from 1.31 to 0.38 for new-to-the-firm innovations, and from 0.58 to 0.27 for new-to-the-market innovations. Hence, the curvature of the inverted- $U$ becomes narrower with acquisition experience. Accordingly, more experienced acquirers are potentially able to attain a higher level of innovative performance in less related acquisitions (supporting Hypothesis 2a), but they also risk of being more adversely affected if the acquisition deviates from the optimal level of industry relatedness (supporting Hypothesis $2 \mathrm{~b}$ ). This is consistent with the consideration that the effect of experience is neither fully positive nor fully negative. As a form of passive learning, acquisition experience enables and reduces risks in selecting and integrating acquisition targets (shifting the position of the curve favorably), but may also generate rigidities because of established routines, when failing to achieve the 'perfect match' in target-acquirer resource configuration (lowering the tolerance of the curve).

\section{ROBUSTNESS ANALYSIS}

To validate whether the estimated relationships reflect the underlying mechanisms, which have been assumed to operate in the innovation process of firms, we split the analysis in two samples. Specifically, we distinguish between firms active in High-tech and Low-tech industries. We expect the hypothesized mechanisms would be stronger in more technological intense environments, in which innovation and organizational renewal are more likely to drive corporate acquisitions. We report the coefficient estimates for the performance equation 
when splitting the sample between firms active in High-tech industries (Table VIa) and in Low-tech industries (Table VIb. ${ }^{8}$ Table VIa shows that, in High-tech firms, overall the inverted U-shaped relationship between innovative performance and industry relatedness still holds; the estimates of the coefficients of the interaction terms are consistent in statistical significance, and reinforce the size of the significant coefficients, as compared to the original estimates for the entire sample. In contrast, in Low-tech firms, effect of industry relatedness on innovative performance is mostly not statistically significant. The comparison shows systematic differences between High-Tech and Low-Tech sectors, suggesting that our assumed mechanisms are typical of High-tech industries, in which corporate acquisitions are more likely motivated by technological innovation.

Finally, to check whether our results are robust to the econometric method used, we estimate the innovation performance equation, as specified previously, using the GMM estimator (2SLS) and instrumenting the lagged value of the dependent variable (i.e. the acquirer's innovation sales in the years preceding acquisition). We model the instrumented variable using the same variables we include in the selection equation of the Heckman model: the innovation obstacles, the acquirer's sectors and time dummies. The Hansen-Sargan tests show that the instruments used are valid ones (the $\mathrm{J}$ statistics and its $\mathrm{p}$-value are reported in the low part of Table VII). As shown in Table VII, the GMM estimates are quite consistent with the estimates we obtained using the two-stage Heckman model. The magnitude and the significance of the coefficients persist across methods, giving a strong support to our results.

This article is protected by copyright. All rights reserved. 


\section{DISCUSSION AND CONCLUSIONS}

This study enriches our understanding of the interdependence between capabilities, relatedness and post-acquisition innovative performance. Specifically, we illustrate the conditions that shape the effect of relatedness on post-acquisition innovative, from a learning capability perspective. Our results show that the acquirer's capabilities in active and passive learning moderate the shape of the relationship between industry relatedness and postacquisition innovative performance, according to distinctive first- and second- order moderating effects.

The extant literature has highlighted that the effect of technological relatedness on post-acquisition innovative performance is curvilinear, according to an inverted-U shape (Ahuja and Katila, 2001; Cloodt et al., 2006; Sears and Hoetker, 2014). From a replication logic, our results confirm the inverted U-shaped relationship in a more general context, when considering the effect of industry relatedness on post-acquisition innovative performance, measured by the sales revenues from innovation. As Ahuja and Katila (2001) point out, a limitation of prior research is that by using patents, as intermediate and imperfect indicators of innovative output, they do not capture the economic returns of inventive activities. More recent studies in this research stream use financial indicators to capture value creation, either the price paid for the acquired firm (Grimpe and Hussinger, 2014) or the cumulative abnormal returns of the acquirer's stock (Sears and Hoetker, 2014). Regarding financial indicators, however, sales revenues from innovation represents a more direct expression of the commercial success of an innovation (Leiponen and Helfat, 2011). Furthermore, while extant definitions of relatedness are based on the proximity or overlap in the contents of the knowledge bases (Makri et al., 2010), our definition is based on inter-business coherence (Teece et al., 1994), which is consistent with a resource-based notion of relatedness (Speckbacher et al., 2015). Specifically, we use a general index of industry relatedness, which 
captures the connections between the resource configurations that matter in different industries, regardless of their specific contents (Bryce and Winter, 2009). Overall, our study extends the technology-based research on relatedness, by accounting for the end outcomes of the overall innovation process and for the possible synergies originating from access to complementary assets and to product markets, which can influence the commercialization and sales revenues of innovations (Cassiman et al., 2005; Puranam et al., 2006). Thus, our findings are important for evaluating the contribution of acquisitions to value creation, generated throughout the innovation process.

Given the curvilinear effect, we then hypothesized that the acquirer's capabilities in active learning (by internal $R \& D$ ) and in passive learning (by acquisition experience) of the acquiring firms can alter the shape of the curvilinear relationship, by influencing two properties of the inverted-U curve: (i) the vertex, which identifies the level of industry relatedness maximizing post-acquisition innovative performance and (ii) the focal-length, which measures the size of the potential losses in post-acquisition innovative performance that would be incurred if industry relatedness is not at the optimal level. Our findings lead to two conclusions. First, capabilities in both active and passive learning exert a similar firstorder moderating effect, shifting the vertex of the inverted-U towards lower industry relatedness. This finding suggests that learning capabilities enhance the integration potential of an acquisition and enable acquirers to exploit the novelty potential of less industry-related acquisitions. Sears and Hoetker (2014) point out to the existence of an interdependence between technological relatedness and technological capabilities (i.e quantity and quality of patents), which can be attributed to an absorptive capacity mechanism, with a monotonic effect on the financial outcomes of acquisitions. Our study extends this approach, and qualifies the underlying mechanisms, by illustrating how the relationship between relatedness

This article is protected by copyright. All rights reserved. 
and value creation depends on in-house $R \& D$ investments and acquisition experience, which reflect the acquirer's absorptive capacity.

Second, our results show that capabilities in active and passive learning have an opposite second-order moderating effect on the inverted-U. While capabilities in active learning increase the focal length, leading to a flatter curve, capabilities in passive learning decreases the focal length, producing a narrower curve. These results suggest that in a situation in which industry relatedness departs from the optimal level, active learning capabilities enhance the re-combinatorial potential of the acquisition, reducing the potential losses in innovative performance with respect to the maximum achievable. Conversely, passive learning capabilities may create rigidities around established routines, which increase potential losses.

Overall, our study contributes to M\&A research by investigating interdependent effects in M\&As (King et al., 2004), with a focus on learning capabilities and resource configurations (Sirmon et al., 2007). It also offers more general conclusions on exploration and exploitation in organizational search. Because acquisitions are a form of external search strategy, our results identify factors that can change the properties of the trade-off between exploration and exploitation in organizational search implied by the inverted-U (Lavie et al., 2010). In particular, they shed further light on the distinction between weak and strong dynamic capabilities in organizational learning research (Levitt and March, 1988; Ng, 2007; Zollo and Winter, 2002). Both weak and strong learning capabilities enhance absorptive capacity facilitating integration between internal and external search, thus shifting the coordinates of the trade-off. Instead, they exert opposite effects on the tolerance of the tradeoff. Strong capabilities, outcome of learning by internal search, can lower the adverse effects of over-exploitation and over-exploration in external search (increasing tolerance). Conversely, weak capabilities, outcome of learning by doing (acquisitions), can enhance the 
risk of a competency trap (Hayward, 2002) when exploration and exploitation efforts are not well balanced (decreasing tolerance).

Our results are robust when comparing two indicators of post-acquisition innovative performance, the sales of new-to-the-firm products and the sales of new-to-the-market products. Some differences also emerge. For new-to-market products, the level of innovative performance achieved at the optimal level of industry relatedness is higher than for new-tothe-firm products, but the tolerance of the curve is lower. This indicates that acquisitions can be more beneficial for innovation in new-to-the market products but at greater risk when failing to reach a balance between the novelty of the acquired resources, and their effective integration, possibly because of the uncertainty of innovating in more novel products. Although we do not elaborate on this aspect, the results are suggestive of the potential of taking into account the novelty of the commercialized products in future M\&A research on relatedness (Makri et al., 2010). Further research could also account for a more refined characterization of the motivations behind acquisitions since it is plausible that the importance of industry relatedness varies for different types of acquisitions. It is also possible that the effect of acquisition experience depends on the specific type of experience whether this concerns related or unrelated domains of activity. As well, more research could extend the attention from the acquirer to the heterogeneous capabilities of the acquired firm (Graebner and Eisenhardt, 2004). Finally, our study offers empirical evidence, based on the observation of the entire range of industrial sectors, of the existence of differences between high-tech and low-tech industries in the factors influencing post-acquisition innovative performance. This evidence can serve as a support to future studies who want to concentrate on either one and to explore the distinctive M\&A dynamics of different technological environments (Haleblian et al., 2009).

This article is protected by copyright. All rights reserved. 
As earlier research points out, the managerial implications of the inverted U-shaped curve is that, in view of the existence of a trade-off between exploration and exploitation in acquisition search, firms should avoid targets that are either too unrelated or too closely related to them in their knowledge bases (Ahuja and Katila, 2001; Cloodt et al., 2006). By indicating firm-specific factors that can alter the shape of this trade-off, our study suggests possible paths for managerial decisions aimed at relaxing the structural boundaries imposed by the search of an optimally related partner. Especially in highly dynamic environments, when uncertainty surrounding innovation is high, managers are hardly able to anticipate what constitutes a 'good target' and to fully know what in-house expertise are required for postacquisition success, a priori (Jovanovic, 1982). At the same time, they are in the situation in which failing to choose an optimal acquisition target implies the greatest losses in terms of potential innovative performance post-acquisition. Our study points out that managers can mitigate this risk, by developing in-house capabilities in active learning, more than in passive learning, and that, by doing so, managers can enhance the organizational tolerance with respect to possible mis-matches in external search.

\section{Notes}

\section{REFERENCES}

Ahuja, G. and Katila, R. (2001). 'Technological acquisitions and the innovation performance of acquiring firms: A longitudinal study'. Strategic Management Journal, 22, 197-220.

Arora, A. and Gambardella, A. (1990). 'Complementarity and external linkages: The strategies of the large firms in biotechnology'. The Journal of Industrial Economics, 38, 361-79.

Barkema, H. G. and Schijven, M. (2008). 'How do firms learn to make acquisitions? A review of past research and an agenda for the future'. Journal of Management, 34, 594-634.

Barney, J. B. (1988). 'Returns to bidding firms in mergers and acquisitions: Reconsidering the relatedness hypothesis'. Strategic Management Journal, 9, 71-78.

Bettis, R., Gambardella, A., Helfat, C. and Mitchell, W. (2014). 'Quantitative empirical analysis in strategic management'. Strategic Management Journal, 35, 949-53.

Brambor, T., Clark, W. and Golder, M. (2006). 'Understanding interaction models: Improving empirical analyses'. Political Analysis, 14, 63-82.

This article is protected by copyright. All rights reserved. 
Breschi, S., Malerba, F. and Orsenigo, L. (2000). 'Technological regimes and schumpeterian patterns of innovation'. The Economic Journal, 110, 388-410.

Bryce, D. J. and Winter, S. G. (2009). 'A general interindustry relatedness index'. Management Science, 55, 1570-85.

Capron, L. and Mitchell, W. (2004). 'Where firms change: Internal development versus external capability sourcing in the global telecommunications industry'. European Management Review, 1, 157-74.

Cassiman, B., Colombo, M. G., Garrone, P. and Veugelers, R. (2005). 'The impact of M\&A on the $\mathrm{R} \& \mathrm{D}$ process an empirical analysis of the role of technological- and market-relatedness'. Research Policy, 34, 195-220.

Cassiman, B. and Veugelers, R. (2002). 'Spillovers and R\&D cooperation: Some empirical evidence'. American Economic Review, 92, 1169-84.

Cassiman, B. and Veugelers, R. (2006). 'In search of complementarity in innovation strategy: Internal R\&D and external knowledge acquisition'. Management Science, 52, 68-82.

Cefis, E. (2010). 'The impact of M\&A on technology sourcing strategies'. Economics of Innovation and New Technology, 19(1), 27-51.

Certo, S. T., Busenbark, J. R., Woo, H.-S. and Semadeni, M. (2016). 'Sample selection bias and Heckman models in strategic management research'. Strategic Management Journal, 37, 2639-57.

Cloodt, M., Hagedoorn, J. and Van Kranenburg, H. (2006). 'Mergers and acquisitions: Their effect on the innovative performance of companies in high-tech industries'. Research Policy, 35, 64254.

Cohen, W. M. and Levinthal, D. A. (1989). 'Innovation and learning: The two faces of R\&D'. The Economic Journal, 99, 569-96.

Cyert, R. M. and March, J. G. (1963). A behavioral theory of the firm. (2) Englewood Cliffs, NJ: Prentice-Hall.

Dosi, G. (1982). 'Technological paradigms and technological trajectories: A suggested interpretation of the determinants and directions of technical change'. Research Policy, 11, 147-62.

Dosi, G. (1988). 'Sources, procedures, and microeconomic effects of innovation'. Journal of economic literature, 26, 1120-71.

Fleming, L. and Sorenson, O. (2004). 'Science as a map in technological search'. Strategic Management Journal, 25, 909-928.

Geroski, P. A., Van Reenen, J. and Walters, C. F. (1997). 'How persistently do firms innovate?'. Research Policy, 26, 33-48.

Graebner, M. E. and Eisenhardt, K. M. (2004). 'The seller's side of the story: Acquisition as courtship and governance as syndicate in entrepreneurial firms'. Administrative Science Quarterly, 49, 366-403.

Graebner, M. E., Eisenhardt, K. M. and Roundy, P. T. (2010). 'Success and failure in technology acquisitions: Lessons for buyers and sellers'. The Academy of Management perspectives, 24, 73-92.

Granstrand, O. and Sjölander, S. (1990). 'The acquisition of technology and small firms by large firms'. Journal of Economic Behavior \& Organization, 13, 367-86.

Greve, H. R. (2007). 'Exploration and exploitation in product innovation'. Industrial and Corporate Change, 16, 945-75.

Grimpe, C. and Hussinger, K. (2014). 'Resource complementarity and value capture in firm acquisitions: The role of intellectual property rights'. Strategic Management Journal, 35, 1762-80.

Haans, R. F., Pieters, C. and He, Z. L. (2015). 'Thinking about u: Theorizing and testing u-and inverted u-shaped relationships in strategy research'. Strategic Management Journal, 37, $1177-95$.

Hagedoorn, J. and Duysters, G. (2002). 'The effect of mergers and acquisitions on the technological performance of companies in a high-tech environment'. Technology Analysis \& Strategic Management, 14, 67-85.

Haleblian, J. and Finkelstein, S. (1999). 'The influence of organizational acquisition experience on acquisition performance: A behavioral learning perspective'. Administrative Science

This article is protected by copyright. All rights reserved. 
Quarterly, 44, 29-56.

Harrison, J. S., Hitt, M. A. and Hoskisson, R. E. (1991). 'Synergies and post-acquisition performance: Differences versus similarities in resource allocations'. Journal of Management, 17, 173-90.

Hayward, M. L. A. (2002). 'When do firms learn from their acquisition experience? Evidence from 1990 to 1995'. Strategic Management Journal, 23, 21-39.

Heckman, J. J. (1979). 'Sample selection bias as a specification error'. Econometrica, 47, 153-61.

Hitt, M., Harrison, J., Ireland, R. D. and Best, A. (1998). 'Attributes of successful and unsuccessful acquisitions of us firms'. British Journal of Management, 9, 91-114.

Kapoor, R. and Lim, K. (2007). 'The impact of acquisitions on the productivity of inventors at semiconductor firms: A synthesis of knowledge-based and incentive-based perspectives'. Academy of Management Journal, 50, 1133-55.

Karim, S. and Mitchell, W. (2000). 'Path-dependent and path-breaking change: Reconfiguring business resources following acquisitions in the U.S. Medical sector, 1978-1995'. Strategic Management Journal, 21, 1061-81.

King, D. R., Dalton, D. R., Daily, C. M. and Covin, J. G. (2004). 'Meta-analyses of post-acquisition performance: Indications of unidentified moderators'. Strategic Management Journal, 25, 187-200.

Klingebiel, R. and Rammer, C. (2014). 'Resource allocation strategy for innovation portfolio management'. Strategic Management Journal, 35, 246-68.

Larsson, R. and Finkelstein, S. (1999). 'Integrating strategic, organizational, and human resource perspectives on mergers and acquisitions: A case survey of synergy realization'. Organization Science, 10, 1-26.

Laursen, K. and Salter, A. (2006). 'Open for innovation: The role of openness in explaining innovation performance among uk manufacturing firms'. Strategic Management Journal, 27, 131-50.

Lavie, D., Stettner, U. and Tushman, M. L. (2010). 'Exploration and exploitation within and across organizations'. Academy of Management Annals, 4, 109-55.

Leiponen, A. and Helfat, C. E. (2010). 'Innovation objectives, knowledge sources, and the benefits of breadth'. Strategic Management Journal, 31, 224-36.

Leiponen, A. and Helfat, C. E. (2011). 'Location, decentralization, and knowledge sources for innovation'. Organization Science, 22, 641-58.

Levitt, B. and March, J. G. (1988). 'Organizational learning'. Annual review of sociology, 14, 319-38.

Love, J. H. and Roper, S. (2002). 'Internal versus external R\&D: A study of R\&D choice with sample selection'. International Journal of the Economics of Business, 9, 239-55.

Mairesse, J. and Mohnen, P. (2002). 'Accounting for innovation and measuring innovativeness: An illustrative framework and an application'. American Economic Review, 92, 226-31.

Makri, M., Hitt, M. A. and Lane, P. J. (2010). 'Complementary technologies, knowledge relatedness, and invention outcomes in high technology mergers and acquisitions'. Strategic Management Journal, 31, 602-28.

March, J. G. (1991). 'Exploration and exploitation in organizational learning'. Organization Science, 2, 71-87.

Nelson, R. R. and Winter, S. G. (1982). An evolutionary theory of economic change. Harvard University Press.

Ng, D. W. (2007). 'A modern resource based approach to unrelated diversification'. Journal of Management Studies, 44, 1481-502.

Pavitt, K. (1984). 'Sectoral patterns of technical change: Towards a taxonomy and a theory'. Research Policy, 13, 343-73.

Pavitt, K. (1985). 'Patent statistics as indicators of innovative activities: Possibilities and problems'. Scientometrics, 7, 77-99.

Phene, A., Tallman, S. and Almeida, P. (2012). 'When do acquisitions facilitate technological exploration and exploitation?'. Journal of Management, 38, 753-83.

Prabhu, J. C., Chandy, R. K. and Ellis, M. E. (2005). 'The impact of acquisitions on innovation: Poison pill, placebo, or tonic?'. Journal of Marketing, 69, 114-30.

Puranam, P., Singh, H. and Zollo, M. (2006). 'Organizing for innovation: Managing the coordinationautonomy dilemma in technology acquisitions'. Academy of Management Journal, 49, 263 -

This article is protected by copyright. All rights reserved. 
80.

Ranft, A. L. and Lord, M. D. (2002). 'Acquiring new technologies and capabilities: A grounded model of acquisition implementation'. Organization Science, 13, 420-41.

Reuer, J. J. and Ragozzino, R. (2008). 'Adverse selection and M\&A design: The roles of alliances and IPOs'. Journal of Economic Behavior \& Organization, 66, 195-212.

Sears, J. and Hoetker, G. (2014). 'Technological overlap, technological capabilities, and resource recombination in technological acquisitions'. Strategic Management Journal, 35, 48-67.

Seth, A. (1990). 'Value creation in acquisitions: A re-examination of performance issues'. Strategic Management Journal, 11, 99-115.

Silverman, B. S. (1999). 'Technological resources and the direction of corporate diversification: Toward an integration of the resource-based view and transaction cost economics'. Management Science, 45, 1109-24.

Sirmon, D. G., Hitt, M. A. and Ireland, R. D. (2007). 'Managing firm resources in dynamic environments to create value: Looking inside the black box'. Academy of Management Review, 32, 273-92.

Speckbacher, G., Neumann, K. and Hoffmann, W. H. (2015). 'Resource relatedness and the mode of entry into new businesses: Internal resource accumulation vs. Access by collaborative arrangement'. Strategic Management Journal, 36, 1675-87.

Teece, D. J. (1986). 'Profiting from technological innovation: Implications for integration, collaboration, licensing and public policy'. Research Policy, 15, 285-305.

Teece, D. J., Rumelt, R., Dosi, G. and Winter, S. (1994). 'Understanding corporate coherence: Theory and evidence'. Journal of Economic Behavior \& Organization, 23, 1-30.

Van Deusen, C. A. and Mueller, C. B. (1999). 'Learning in acquisitions: Understanding the relationship between exploration, exploitation and performance'. The Learning Organization, 6, 186-93.

Veugelers, R. and Cassiman, B. (1999). 'Make and buy in innovation strategies: Evidence from Belgian manufacturing firms'. Research Policy, 28, 63-80.

Wooldridge, J. M. (2010). Econometric analysis of cross section and panel data. Cambridge, MA: MIT press.

Zahra, S. and George, G. (2002). 'Absorptive capacity: A review, reconceptualization, and extension'. Academy of Management Review, 27, 185-203.

Zollo, M. and Singh, H. (2004). 'Deliberate learning in corporate acquisitions: Post-acquisition strategies and integration capability in U.S. Bank mergers'. Strategic Management Journal, 25, 1233-56.

Zollo, M. and Winter, S. G. (2002). 'Deliberate learning and the evolution of dynamic capabilities'. Organization Science, 13, 339-51.

This article is protected by copyright. All rights reserved. 
${ }^{1}$ A curvilinear, inverted U-shaped, effect of technological relatedness is also observed for some dimensions of financial performance, such as the price paid by the acquirer for the target (Grimpe and Hussinger, 2014), but not for others, such as the cumulative abnormal returns of the acquirer's stock (Sears and Hoetker, 2014).

${ }^{2}$ Ahuja and Katila (2001) measure the absolute size of the knowledge basis using the number of patents prior to the acquisition, observing however that this is highly correlated (0.89) with the yearly R\&D expenditures.

${ }^{3}$ ABR stands for Algemeen Bedrijven Register.

4 While earlier studies test for moderating effects to the curvilinear relationship, by assuming a linear specification of the moderator in the interaction with the square of relatedness, that is $\gamma Z X^{2}$, in the equation of the parabola (Haans et al, 2015) we use a quadratic specification, that is $\gamma Z^{2} X^{2}$, which maintains the symmetry in the way both components of the interaction term enter the equation. When expressing moderating effects of the first-order in the form of interaction terms, e.g. $\delta Z X$, the moderator and the explanatory variable enter in the same manner, and the interpretation of the coefficient is symmetric. In other words, the coefficient $\delta$ measures the effect of $X$ conditional on $Z$, as well as the effect of $Z$ conditional on $X$. Hence, the reason to transform both variable in their squares is to maintain the same type of symmetry in the interpretation of the coefficient $\gamma$ also for the second-order moderating effects. This is equivalent to assume the possibility that the moderators affect the dependent variable in a non-linear relationship, as it has been observed for R\&D expenditures and post-acquisition patenting (Cloodt et al., 2006) and for acquisition experience and post-acquisition performance (Barkema and Schijven, 2008).

${ }^{5}$ The results are available on request.

${ }^{6}$ The shift in the parabola towards the left-hand side with increasing R\&D is confirmed also by the negative and statistically significant coefficient in the model with only the linear interaction terms, holding constant the curvature or focal length of the curvilinear relationship

7 The shift in the parabola towards the left-hand side with increasing acquisition experience is confirmed also by the negative and statistically significant coefficient in the model with only the linear interaction terms, holding constant the curvature or focal length of the curvilinear relationship.

8 Tables VIa and VIb contain the estimates for new-to-firm innovative sales, as dependent variable, only. The results for new-to-market innovative sales are largely robust, and are available upon request.

This article is protected by copyright. All rights reserved. 
Table I. Descriptive statistics and correlation matrix.

\begin{tabular}{|c|c|c|c|c|c|c|c|c|c|c|c|c|c|c|c|c|c|c|c|c|c|c|c|}
\hline Variable & Mean & St.d. & 1 & 2 & 3 & 4 & 5 & 6 & 7 & 8 & 9 & 10 & 11 & 12 & 13 & 14 & 15 & 16 & 17 & 18 & 19 & 20 & 21 \\
\hline 1. New-to-firm innovation sales & 7.42 & 3.06 & 1 & & & & & & & & & & & & & & & & & & & & \\
\hline 2. New-to-market innovation sales & 7.68 & 2.65 & 0.79 & 1 & & & & & & & & & & & & & & & & & & & \\
\hline 3. Relatedness & 3.74 & 1.17 & -0.09 & -0.13 & 1 & & & & & & & & & & & & & & & & & & \\
\hline 4. Acquisition experience & 1.55 & 1.23 & 0.1 & 0.04 & 0.10 & 1 & & & & & & & & & & & & & & & & & \\
\hline 9. R\&D intensity & 1.68 & 2.87 & 0.26 & 0.27 & -0.13 & -0.5 & 1 & & & & & & & & & & & & & & & & \\
\hline 5. Acquirer age & 2.31 & 1.28 & 0.07 & 0.03 & -0.09 & 0.01 & 0.05 & 1 & & & & & & & & & & & & & & & \\
\hline 6. Acquirer size & 5.77 & 1.16 & 0.28 & 0.29 & 0.04 & 0.49 & 0.19 & 0.06 & 1 & & & & & & & & & & & & & & \\
\hline 7. Target age & 1.94 & 1.18 & 0.00 & 0.07 & 0.16 & -0.1 & -0.01 & -0.05 & 0.00 & 1 & & & & & & & & & & & & & \\
\hline 8. Target size & 2.35 & 1.82 & 0.09 & 0.13 & 0.24 & -0.26 & 0.05 & -0.2 & 0.12 & 0.41 & 1 & & & & & & & & & & & & \\
\hline 10. Financial constraints & 0.16 & 0.36 & 0.05 & -0.09 & 0.02 & -0.07 & 0.06 & -0.08 & -0.05 & -0.06 & 0.04 & 1 & & & & & & & & & & & \\
\hline 11. Lack of knowledge & 0.29 & 0.45 & -0.02 & 0.08 & -0.04 & -0.02 & 0.24 & -0.1 & 0.1 & 0.02 & 0.05 & 0.44 & 1 & & & & & & & & & & \\
\hline 12. Market uncertainty & 0.22 & 0.41 & -0.05 & 0.02 & -0.02 & -0.04 & 0.26 & -0.05 & 0.03 & 0.04 & 0.02 & 0.45 & 0.59 & 1 & & & & & & & & & \\
\hline 13. Acquirer high tech manuf. & 0.05 & 0.22 & 0.05 & -0.02 & -0.13 & -0.16 & 0.19 & 0.04 & -0.09 & 0.03 & 0.05 & 0.02 & -0.02 & 0.00 & 1 & & & & & & & & \\
\hline 14. Acquirer low tech manuf. & 0.13 & 0.34 & 0.12 & 0.03 & -0.08 & -0.23 & 0.18 & 0.04 & 0.00 & 0.01 & 0.13 & 0.09 & 0.09 & 0.09 & -0.09 & 1 & & & & & & & \\
\hline 15. Acquirer high KI services & 0.25 & 0.43 & -0.10 & -0.11 & 0.02 & -0.02 & 0.18 & -0.1 & 0.00 & -0.16 & -0.12 & 0.02 & 0.01 & -0.02 & -0.14 & -0.23 & 1 & & & & & & \\
\hline 16. Acquirer low KI services & 0.41 & 0.49 & 0.00 & -0.02 & 0.16 & 0.15 & -0.37 & 0.00 & 0.00 & 0.12 & 0.05 & -0.08 & -0.08 & -0.14 & -0.2 & -0.33 & -0.49 & 1 & & & & & \\
\hline 17. Acquirer construction & 0.13 & 0.34 & -0.07 & 0.16 & -0.09 & 0.13 & -0.01 & 0.06 & 0.06 & 0.00 & -0.09 & -0.02 & 0.02 & 0.13 & -0.09 & -0.16 & -0.24 & -0.34 & 1 & & & & \\
\hline 18. Target high tech manuf. & 0.03 & 0.18 & -0.06 & -0.08 & -0.03 & -0.1 & 0.15 & 0.00 & -0.03 & 0.04 & 0.1 & 0.03 & 0.01 & 0.04 & 0.52 & -0.01 & -0.11 & -0.11 & -0.03 & 1 & & & \\
\hline 19. Target low tech manuf. & 0.08 & 0.27 & 0.07 & 0.05 & 0.1 & -0.19 & 0.13 & -0.01 & -0.06 & 0.06 & 0.17 & 0.06 & 0.08 & 0.07 & -0.02 & 0.62 & -0.17 & -0.2 & -0.09 & -0.05 & 1 & & \\
\hline 20. Target high KI services & 0.42 & 0.49 & -0.05 & -0.01 & 0.34 & 0.05 & 0.12 & 0.00 & 0.04 & 0.26 & -0.28 & 0.02 & 0.03 & 0.00 & -0.1 & -0.1 & 0.64 & -0.48 & 0.04 & -0.16 & -0.25 & 1 & \\
\hline 21. Target low KI services & 0.39 & 0.48 & 0.04 & -0.03 & 0.24 & 0.1 & -0.24 & 0.02 & 0.00 & 0.17 & 0.09 & -0.06 & -0.08 & -0.1 & -0.06 & -0.2 & -0.44 & 0.75 & -0.27 & -0.15 & -0.24 & -0.69 & 1 \\
\hline 22. Target construction & 0.07 & 0.25 & -0.01 & 0.10 & 0.11 & -0.01 & -0.01 & -0.02 & 0.00 & 0.08 & 0.11 & 0.02 & 0.01 & 0.08 & -0.02 & -0.08 & -0.14 & -0.21 & 0.56 & -0.05 & -0.08 & -0.23 & -0.22 \\
\hline
\end{tabular}

Note: $\mathrm{N}=1736$

This article is protected by copyright. All rights reserved. 
Table II: Post-acquisition innovative status grouped by acquirer firm's industry.

\begin{tabular}{lccc}
\hline Acquirer industry & $\begin{array}{c}\text { Post-acquisition } \\
\text { innovator }\end{array}$ & Total & \% Innovator \\
\hline High tech manufacturing & 50 & 92 & 0.54 \\
Low tech manufacturing & 129 & 237 & 0.54 \\
High Knowledge intensive service & 168 & 448 & 0.38 \\
Low knowledge intensive service & 95 & 717 & 0.13 \\
Construction & 70 & 242 & 0.29 \\
\hline Total & 512 & 1,736 & 0.29 \\
\hline
\end{tabular}

Table III: Estimates of selection equation for post-acquisition innovation

\begin{tabular}{lcc}
\hline Variable & Model 1 & Model 2 \\
& New to the firm & New to the market \\
\hline Financial constraints & $-0.378^{* * *}$ & $-0.316^{* *}$ \\
& $(0.117)$ & $(0.128)$ \\
Lack of knowledge & $0.563^{* * *}$ & $0.409^{* * *}$ \\
Market uncertainty & $(0.108)$ & $(0.121)$ \\
& $0.663^{* * *}$ & $0.700^{* * *}$ \\
Acquirer age & $(0.111)$ & $(0.122)$ \\
& -0.029 & $-0.069^{* *}$ \\
Acquirer size & $(0.031)$ & $(0.034)$ \\
& $0.110^{* * *}$ & $0.140^{* * *}$ \\
Time dummies & $(0.032)$ & $(0.035)$ \\
Sector dummies & & yes \\
Constant & yes & yes \\
& & $-0.735^{* *}$ \\
Les $\chi^{2}(20)$ & -0.382 & $(0.349)$ \\
Lseudo $\mathrm{R}^{2}$ & $(0.311)$ & 319.39 \\
\hline
\end{tabular}

Note: $\mathrm{N}=1,736$. Robust standard errors are in parentheses. $* * * \mathrm{p}<0.01, * * \mathrm{p}<0.05, * \mathrm{p}<0.1$

This article is protected by copyright. All rights reserved. 
Table IV. Estimates of performance equation for post-acquisition new-to-the-firm and newto-the-market innovation sales

\begin{tabular}{|c|c|c|c|c|c|c|}
\hline VARIABLES & $\begin{array}{l}\text { NEW FIRM } \\
\text { mod.1 }\end{array}$ & $\begin{array}{l}\text { NEW FIRM } \\
\text { mod. } 2\end{array}$ & $\begin{array}{l}\text { NEW FIRM } \\
\text { mod.3 }\end{array}$ & $\begin{array}{l}\text { NEW MKT } \\
\text { mod.1a }\end{array}$ & $\begin{array}{l}\text { NEW MKT } \\
\text { mod. } 2 a\end{array}$ & $\begin{array}{l}\text { NEW MKT } \\
\text { mod. } 3 a\end{array}$ \\
\hline Innovative sales (t-1) & $\begin{array}{l}0.0716 * * \\
(0.0364)\end{array}$ & $\begin{array}{l}0.113 * * * \\
(0.0361)\end{array}$ & $\begin{array}{l}0.0975 * * * \\
(0.0352)\end{array}$ & $\begin{array}{l}0.0191 \\
(0.0368)\end{array}$ & $\begin{array}{l}0.0752 * * \\
(0.0361)\end{array}$ & $\begin{array}{l}0.0475 \\
(0.0341)\end{array}$ \\
\hline Relatedness (ln) & $\begin{array}{l}3.044 * * \\
(1.202)\end{array}$ & $\begin{array}{l}3.236 * * * \\
(1.165)\end{array}$ & $\begin{array}{l}1.488 \\
(1.241)\end{array}$ & $\begin{array}{l}5.546 * * * \\
(1.097)\end{array}$ & $\begin{array}{l}5.314 * * * \\
(1.042)\end{array}$ & $\begin{array}{l}3.159 * * * \\
(1.112)\end{array}$ \\
\hline Relatedness $^{2}(\ln )^{2}$ & $\begin{array}{l}-0.472 * * * \\
(0.172)\end{array}$ & $\begin{array}{l}-0.458 * * * \\
(0.167)\end{array}$ & $\begin{array}{l}-0.185 \\
(0.172)\end{array}$ & $\begin{array}{l}-0.855 * * * \\
(0.157)\end{array}$ & $\begin{array}{l}-0.782 * * * \\
(0.150)\end{array}$ & $\begin{array}{l}-0.427 * * * \\
(0.154)\end{array}$ \\
\hline Acquisition experience (ln) & $\begin{array}{l}-0.929 * * \\
(0.407)\end{array}$ & $\begin{array}{l}-0.650 \\
(0.397)\end{array}$ & $\begin{array}{l}-3.364 * * * \\
(1.242)\end{array}$ & $\begin{array}{l}-0.271 \\
(0.383)\end{array}$ & $\begin{array}{l}-0.0354 \\
(0.365)\end{array}$ & $\begin{array}{l}-2.539 * * \\
(1.134)\end{array}$ \\
\hline Acquisition experience $^{2}(\ln )^{2}$ & $\begin{array}{l}0.343 * * \\
(0.140)\end{array}$ & $\begin{array}{l}0.246^{*} \\
(0.136)\end{array}$ & $\begin{array}{l}1.128 * * * \\
(0.263)\end{array}$ & $\begin{array}{l}0.0781 \\
(0.130)\end{array}$ & $\begin{array}{l}-0.00534 \\
(0.124)\end{array}$ & $\begin{array}{l}0.873 * * * \\
(0.237)\end{array}$ \\
\hline R\&D intensity (ln) & $\begin{array}{l}0.160 * * * \\
(0.0494)\end{array}$ & $\begin{array}{l}0.658 * * * \\
(0.137)\end{array}$ & $\begin{array}{l}0.663 * * * \\
(0.133)\end{array}$ & $\begin{array}{l}0.126 * * * \\
(0.0473)\end{array}$ & $\begin{array}{l}0.554 * * * \\
(0.122)\end{array}$ & $\begin{array}{l}0.598 * * * \\
(0.115)\end{array}$ \\
\hline Relatedness $x$ R\&D intensity & & $\begin{array}{l}-0.310 * * * \\
(0.0567)\end{array}$ & $\begin{array}{l}-0.305^{* * * *} \\
(0.0550)\end{array}$ & & $\begin{array}{l}-0.291 * * * \\
(0.0511)\end{array}$ & $\begin{array}{l}-0.294 * * * \\
(0.0480)\end{array}$ \\
\hline (Relatedness $x$ R\&D intensity) $^{2}$ & & $\begin{array}{l}0.00553 * * * \\
(0.000985)\end{array}$ & $\begin{array}{l}0.00556 * * * \\
(0.000957)\end{array}$ & & $\begin{array}{l}0.00539 * * * \\
(0.000868)\end{array}$ & $\begin{array}{l}0.00542 * * * \\
(0.000817)\end{array}$ \\
\hline Relatedness x Acquisition experience & & & $\begin{array}{l}0.736 * * \\
(0.322)\end{array}$ & & & $\begin{array}{l}0.699 * * \\
(0.295)\end{array}$ \\
\hline (Relatedness x Acquisition experience) $^{2}$ & & & $\begin{array}{l}-0.0597 * * * \\
(0.0154)\end{array}$ & & & $\begin{array}{l}-0.0621 * * * \\
(0.0143)\end{array}$ \\
\hline Target age $(\ln )$ & $\begin{array}{l}0.101 \\
(0.118)\end{array}$ & $\begin{array}{l}0.0869 \\
(0.114)\end{array}$ & $\begin{array}{l}0.0553 \\
(0.111)\end{array}$ & $\begin{array}{l}0.0296 \\
(0.112)\end{array}$ & $\begin{array}{l}0.0421 \\
(0.106)\end{array}$ & $\begin{array}{l}-0.00731 \\
(0.100)\end{array}$ \\
\hline Target size $(\ln )$ & $\begin{array}{l}0.0149 \\
(0.0808)\end{array}$ & $\begin{array}{l}-0.0372 \\
(0.0787)\end{array}$ & $\begin{array}{l}-0.0567 \\
(0.0769)\end{array}$ & $\begin{array}{l}0.163 * * \\
(0.0742)\end{array}$ & $\begin{array}{l}0.0869 \\
(0.0716)\end{array}$ & $\begin{array}{l}0.0480 \\
(0.0680)\end{array}$ \\
\hline Acquirer age (ln) & $\begin{array}{l}-0.0385 \\
(0.113)\end{array}$ & $\begin{array}{l}-0.0262 \\
(0.109)\end{array}$ & $\begin{array}{l}-0.0775 \\
(0.107)\end{array}$ & $\begin{array}{l}-0.167 \\
(0.108)\end{array}$ & $\begin{array}{l}-0.113 \\
(0.103)\end{array}$ & $\begin{array}{l}-0.202 * * \\
(0.0986)\end{array}$ \\
\hline Acquirer size (ln) & $\begin{array}{l}0.904 * * * \\
(0.139)\end{array}$ & $\begin{array}{l}0.670^{* * * *} \\
(0.143)\end{array}$ & $\begin{array}{l}0.720 * * * \\
(0.140)\end{array}$ & $\begin{array}{l}0.625 * * * \\
(0.139)\end{array}$ & $\begin{array}{l}0.411 * * * \\
(0.138)\end{array}$ & $\begin{array}{l}0.507 * * * \\
(0.132)\end{array}$ \\
\hline Dummies for technological regimes & yes & yes & yes & yes & yes & yes \\
\hline Time dummies (form 1997 til 2004) & yes & yes & yes & yes & yes & yes \\
\hline Constant & $\begin{array}{l}-4.598 * * \\
(2.261)\end{array}$ & $\begin{array}{l}-3.729 * \\
(2.240)\end{array}$ & $\begin{array}{l}-1.618 \\
(2.419)\end{array}$ & $\begin{array}{l}-4.141^{* * *} \\
(2.104)\end{array}$ & $\begin{array}{l}-2.975 \\
(2.042)\end{array}$ & $\begin{array}{l}-0.945 \\
(2.150)\end{array}$ \\
\hline Mills $(\lambda)$ & $\begin{array}{l}1.445 * * * \\
(0.438)\end{array}$ & $\begin{array}{l}1.329 * * * \\
(0.423)\end{array}$ & $\begin{array}{l}1.538 * * * \\
(0.417)\end{array}$ & $\begin{array}{l}0.488 \\
(0.396)\end{array}$ & $\begin{array}{l}0.541 \\
(0.377)\end{array}$ & $\begin{array}{l}0.919 * * \\
(0.367)\end{array}$ \\
\hline Wald $\chi^{2}$ & 153.1 & 196.9 & 238.1 & 234.4 & 298.9 & 382.0 \\
\hline Rho & 0.498 & 0.477 & 0.553 & 0.233 & 0.270 & 0.465 \\
\hline
\end{tabular}

Note: $\mathrm{N}=1,736$. Uncensored observations for NEW to the FIRM models $=512$. Uncensored observations for NEW to the MARKET

models $=362$. Robust standard errors are in parentheses. $* \mathrm{p}<0.10, * * \mathrm{p}<0.05, * * * \mathrm{p}<0.01$ (two-tailed test)

This article is protected by copyright. All rights reserved. 
Table V. Parameters of the curvilinear relationship of post-acquisition new-to-the-firm and new-to-the-market innovation sales and industry relatedness

\begin{tabular}{lcccccc}
\hline & \multicolumn{3}{c}{ New to the firm (a) } & \multicolumn{3}{c}{ New to the market (b) } \\
Moderating variable & $\begin{array}{c}\text { Vertex x- } \\
\text { coordinate }\end{array}$ & $\begin{array}{c}\text { Vertex y- } \\
\text { coordinate }\end{array}$ & $\begin{array}{c}\text { Focal } \\
\text { length }\end{array}$ & $\begin{array}{c}\text { Vertex x- } \\
\text { coordinate }\end{array}$ & $\begin{array}{c}\text { Vertex y- } \\
\text { coordinate }\end{array}$ & $\begin{array}{c}\text { Focal } \\
\text { length }\end{array}$ \\
\hline $\begin{array}{l}\text { Direct effects (mod.1 and la) } \\
\text { Moderating effects (mod.3 and 3a) }\end{array}$ & 3.22 & 5.85 & 0.53 & 3.24 & 8.64 & 0.29 \\
R\&D intensity & & & & & & \\
$\quad$ Low & 2.88 & 5.33 & 1.48 & 3.24 & 7.42 & 0.61 \\
$\quad$ High & 1.64 & 5.56 & 2.30 & 2.93 & 7.36 & 0.71 \\
Acquisition experience & & & & & & \\
$\quad$ Low & 4.51 & 5.40 & 1.31 & 3.90 & 7.23 & 0.58 \\
$\quad$ High & 2.72 & 6.70 & 0.38 & 2.81 & 8.23 & 0.27 \\
\hline
\end{tabular}

This article is protected by copyright. All rights reserved. 
Table VIa. Robustness analysis: estimates of performance equation for post-acquisition newto-the-firm and new-to-the-market innovation sales, in High-tech

\begin{tabular}{|c|c|c|c|c|c|c|}
\hline VARIABLES & $\begin{array}{l}\text { NEW } \\
\text { FIRM } \\
\text { mod.1 }\end{array}$ & $\begin{array}{l}\text { NEW } \\
\text { FIRM } \\
\text { mod.2 }\end{array}$ & $\begin{array}{l}\text { NEW FIRM } \\
\text { mod.3 }\end{array}$ & $\begin{array}{l}\text { NEW } \\
\text { MKT } \\
\text { mod.1a }\end{array}$ & $\begin{array}{l}\text { NEW MKT } \\
\text { mod. } 2 a\end{array}$ & $\begin{array}{l}\text { NEW MKT } \\
\text { mod.3a }\end{array}$ \\
\hline \multirow[t]{2}{*}{ Innovative sales (t-1) } & -0.0306 & 0.0311 & -0.00380 & -0.0115 & 0.0775 & 0.0162 \\
\hline & $(0.0545)$ & $(0.0543)$ & $(0.0501)$ & $(0.0529)$ & $(0.0498)$ & $(0.0450)$ \\
\hline \multirow[t]{2}{*}{ Relatedness (ln) } & $4.561 * * *$ & $3.866 * * *$ & -0.832 & $7.467 * * *$ & $6.887 * * *$ & 1.720 \\
\hline & $(1.446)$ & $(1.397)$ & $(1.527)$ & $(1.274)$ & $(1.160)$ & $(1.242)$ \\
\hline \multirow[t]{2}{*}{ Relatedness $^{2}(\ln )^{2}$} & $-0.755 * * *$ & $-0.603 * * *$ & 0.112 & $-1.142 * * *$ & $-1.016^{* * *}$ & -0.258 \\
\hline & $(0.209)$ & $(0.205)$ & $(0.216)$ & $(0.184)$ & $(0.170)$ & $(0.176)$ \\
\hline \multirow[t]{2}{*}{ Acquisition experience (ln) } & -0.776 & -0.177 & $-5.568 * * *$ & -0.374 & 0.313 & $-5.554 * * *$ \\
\hline & $(0.581)$ & $(0.574)$ & $(1.546)$ & $(0.534)$ & $(0.498)$ & $(1.316)$ \\
\hline \multirow[t]{2}{*}{ Acquisition experience $^{2}(\ln )^{2}$} & 0.295 & 0.0827 & $1.541 * * *$ & 0.163 & -0.116 & $1.348 * * *$ \\
\hline & $(0.205)$ & $(0.202)$ & $(0.322)$ & $(0.183)$ & $(0.172)$ & $(0.271)$ \\
\hline \multirow[t]{2}{*}{ R\&D intensity (ln) } & $0.180 * *$ & $0.635 * * *$ & $0.686 * * *$ & 0.105 & $0.449 * * *$ & $0.534 * * *$ \\
\hline & $(0.0721)$ & $(0.197)$ & $(0.181)$ & $(0.0670)$ & $(0.161)$ & $(0.142)$ \\
\hline \multirow[t]{2}{*}{ Relatedness x R\&D intensity } & & $-0.325 * * *$ & $-0.342 * * *$ & & $-0.313 * * *$ & $-0.340 * * *$ \\
\hline & & $(0.0820)$ & $(0.0758)$ & & $(0.0678)$ & $(0.0590)$ \\
\hline \multirow[t]{2}{*}{ (Relatedness $x$ R\&D intensity) $^{2}$} & & $0.00624 * * *$ & $0.00662 * * *$ & & $0.00671 * * *$ & $0.00734 * * *$ \\
\hline & & $(0.00131)$ & $(0.00122)$ & & $(0.00104)$ & $(0.000924)$ \\
\hline \multirow[t]{2}{*}{ Relatedness x Acquisition experience } & & & $1.634 * * *$ & & & $1.736 * * *$ \\
\hline & & & $(0.431)$ & & & $(0.360)$ \\
\hline \multirow[t]{2}{*}{ (Relatedness x Acquisition experience) $^{2}$} & & & $-0.118 * * *$ & & & $-0.114 * * *$ \\
\hline & & & $(0.0212)$ & & & $(0.0176)$ \\
\hline \multirow[t]{2}{*}{ Target age (ln) } & 0.254 & 0.247 & 0.0996 & $0.301 * *$ & $0.263^{*}$ & 0.192 \\
\hline & $(0.171)$ & $(0.164)$ & $(0.152)$ & $(0.149)$ & $(0.136)$ & $(0.119)$ \\
\hline \multirow[t]{2}{*}{ Target size (ln) } & 0.0703 & -0.0229 & -0.0994 & 0.143 & 0.0263 & -0.0629 \\
\hline & $(0.113)$ & $(0.110)$ & $(0.102)$ & $(0.0988)$ & $(0.0913)$ & $(0.0810)$ \\
\hline \multirow[t]{2}{*}{ Acquirer age (ln) } & 0.0960 & 0.143 & -0.0455 & -0.148 & -0.0732 & -0.186 \\
\hline & $(0.172)$ & $(0.165)$ & $(0.155)$ & $(0.163)$ & $(0.148)$ & $(0.134)$ \\
\hline \multirow[t]{2}{*}{ Acquirer size (ln) } & $0.834 * * *$ & $0.631 * * *$ & $0.727 * * *$ & $0.818 * * *$ & $0.525 * * *$ & $0.672 * * *$ \\
\hline & $(0.195)$ & $(0.193)$ & $(0.178)$ & $(0.188)$ & $(0.176)$ & $(0.159)$ \\
\hline Dummies for technological regimes & yes & yes & yes & yes & yes & yes \\
\hline Time dummies (form 1997 til 2004) & yes & yes & yes & yes & yes & yes \\
\hline \multirow[t]{2}{*}{ Constant } & $-6.410 * *$ & -4.508 & 2.432 & $-8.364 * * *$ & $-5.484 * *$ & 1.294 \\
\hline & $(2.795)$ & $(2.751)$ & $(3.021)$ & $(2.529)$ & $(2.337)$ & $(2.472)$ \\
\hline \multirow[t]{2}{*}{ Mills $(\lambda)$} & $1.673 * * *$ & $1.513 * * *$ & $1.463 * * *$ & $1.236 * * *$ & $1.030 * *$ & $1.370 * * *$ \\
\hline & $(0.522)$ & $(0.501)$ & $(0.461)$ & $(0.459)$ & $(0.414)$ & $(0.379)$ \\
\hline Wald $\chi^{2}$ & 104.1 & 135.9 & 210.0 & 144.3 & 219.5 & 329.9 \\
\hline Rho & 0.577 & 0.550 & 0.575 & 0.569 & 0.532 & 0.730 \\
\hline
\end{tabular}

Note: $\mathrm{N}=719$ for New-to-the-firm. $\mathrm{N}=645$ for New-to-the-market. Robust standard errors are in parentheses. $* \mathrm{p}<0.10, * * \mathrm{p}<0.05, * * * \mathrm{p}$ $<0.01$

This article is protected by copyright. All rights reserved. 
Table VIb. Robustness analysis: estimates of performance equation for post-acquisition newto-firm and new-to-the-market innovation sales, in Low-tech

\begin{tabular}{|c|c|c|c|c|c|c|}
\hline VARIABLES & $\begin{array}{l}\text { NEW FIRM } \\
\operatorname{mod.1}\end{array}$ & $\begin{array}{l}\text { NEW FIRM } \\
\bmod 2\end{array}$ & $\begin{array}{l}\text { NEW FIRM } \\
\text { mod.3 }\end{array}$ & $\begin{array}{l}\text { NEW MKT } \\
\text { mod.1a }\end{array}$ & $\begin{array}{l}\text { NEW MKT } \\
\bmod .2 a\end{array}$ & $\begin{array}{l}\text { NEW MKT } \\
\text { mod. } 3 a\end{array}$ \\
\hline \multirow[t]{2}{*}{ Innovative sales ( $\mathrm{t}-1$ ) } & $0.183 * * *$ & $0.174 * * *$ & $0.168 * * *$ & $0.151 * * *$ & $0.130 * * *$ & $0.125^{* *}$ \\
\hline & $(0.0476)$ & $(0.0486)$ & $(0.0489)$ & $(0.0499)$ & $(0.0496)$ & $(0.0487)$ \\
\hline \multirow[t]{2}{*}{ Relatedness (ln) } & -2.678 & -2.676 & -2.392 & 1.064 & 0.996 & 0.758 \\
\hline & $(2.054)$ & $(2.065)$ & $(2.114)$ & $(1.952)$ & $(1.907)$ & $(1.910)$ \\
\hline \multirow[t]{2}{*}{ Relatedness $^{2}(\ln )^{2}$} & 0.389 & 0.417 & 0.398 & -0.167 & -0.107 & -0.0408 \\
\hline & $(0.290)$ & $(0.291)$ & $(0.293)$ & $(0.276)$ & $(0.270)$ & $(0.267)$ \\
\hline \multirow[t]{2}{*}{ Acquisition experience (ln) } & $-1.208 * *$ & $-1.180 * *$ & -0.986 & -0.573 & -0.615 & -2.298 \\
\hline & $(0.586)$ & $(0.586)$ & $(1.952)$ & $(0.580)$ & $(0.575)$ & $(1.801)$ \\
\hline \multirow[t]{2}{*}{ Acquisition experience $^{2}(\ln )^{2}$} & $0.602 * * *$ & $0.614 * * *$ & 0.688 & 0.178 & 0.228 & $0.719^{*}$ \\
\hline & $(0.232)$ & $(0.233)$ & $(0.427)$ & $(0.229)$ & $(0.228)$ & $(0.390)$ \\
\hline \multirow[t]{2}{*}{ R\&D intensity (ln) } & $0.235^{* * *}$ & $0.564 * * *$ & $0.616 * * *$ & 0.0926 & $0.532 * * *$ & $0.703 * * *$ \\
\hline & $(0.0657)$ & $(0.201)$ & $(0.206)$ & $(0.0686)$ & $(0.189)$ & $(0.201)$ \\
\hline \multirow[t]{2}{*}{ Relatedness x R\&D intensity } & & -0.102 & -0.122 & & -0.0945 & $-0.164 * *$ \\
\hline & & $(0.0847)$ & $(0.0867)$ & & $(0.0796)$ & $(0.0837)$ \\
\hline \multirow[t]{2}{*}{ (Relatedness $x$ R\&D intensity) $^{2}$} & & 0.000423 & 0.000688 & & -0.000946 & -0.000257 \\
\hline & & $(0.00160)$ & $(0.00162)$ & & $(0.00154)$ & $(0.00154)$ \\
\hline \multirow[t]{2}{*}{ Relatedness x Acquisition experience } & & & -0.0145 & & & 0.563 \\
\hline & & & $(0.511)$ & & & $(0.482)$ \\
\hline \multirow[t]{2}{*}{${\text { (Relatedness x Acquisition experience })^{2}}^{2}$} & & & -0.00937 & & & $-0.0480 *$ \\
\hline & & & $(0.0275)$ & & & $(0.0268)$ \\
\hline \multirow[t]{2}{*}{ Target age (ln) } & -0.0556 & -0.0183 & -0.0168 & -0.226 & -0.159 & -0.141 \\
\hline & $(0.151)$ & $(0.152)$ & $(0.152)$ & $(0.159)$ & $(0.159)$ & $(0.157)$ \\
\hline \multirow[t]{2}{*}{ Target size (ln) } & -0.103 & -0.113 & -0.1000 & 0.130 & 0.0994 & 0.104 \\
\hline & $(0.115)$ & $(0.114)$ & $(0.115)$ & $(0.114)$ & $(0.112)$ & $(0.111)$ \\
\hline \multirow[t]{2}{*}{ Acquirer age (ln) } & $-0.314^{* *}$ & $-0.303 * *$ & $-0.305^{* *}$ & $-0.390 * * *$ & $-0.367 * *$ & $-0.414 * * *$ \\
\hline & $(0.147)$ & $(0.146)$ & $(0.146)$ & $(0.148)$ & $(0.144)$ & $(0.144)$ \\
\hline \multirow[t]{2}{*}{ Acquirer size (ln) } & $0.498^{* *}$ & $0.483^{* *}$ & $0.519^{* *}$ & $0.508 * *$ & $0.605^{* *}$ & $0.708 * * *$ \\
\hline & $(0.196)$ & $(0.218)$ & $(0.220)$ & $(0.219)$ & $(0.236)$ & $(0.235)$ \\
\hline Dummies for technological regimes & yes & yes & yes & yes & yes & yes \\
\hline Time dummies (form 1997 til 2004) & yes & yes & yes & yes & yes & yes \\
\hline \multirow[t]{2}{*}{ Constant } & $7.137 *$ & $6.728^{*}$ & 5.784 & 3.138 & 1.609 & 1.122 \\
\hline & (3.674) & $(3.655)$ & $(3.846)$ & $(3.639)$ & $(3.573)$ & $(3.663)$ \\
\hline \multirow[t]{2}{*}{ Mills $(\lambda)$} & 0.691 & 0.646 & 0.623 & 0.398 & 0.408 & 0.369 \\
\hline & $(0.600)$ & $(0.596)$ & $(0.604)$ & $(0.416)$ & $(0.410)$ & $(0.402)$ \\
\hline Wald $\chi^{2}$ & 131.7 & 137.3 & 139.2 & 178.2 & 198.3 & 212.2 \\
\hline Rho & 0.306 & 0.289 & 0.280 & 0.222 & 0.234 & 0.217 \\
\hline
\end{tabular}

Note: $\mathrm{N}=744$ for New-to-the-firm. $\mathrm{N}=684$ for New-to-the-market. Robust standard errors are in parentheses. $* \mathrm{p}<0.10, * * \mathrm{p}<0.05,{ }^{* * *} \mathrm{p}$ $<0.01$ 
Table VII. Robustness analysis: GMM estimator with lagged innovative sales instrumented.

\begin{tabular}{|c|c|c|c|c|c|c|}
\hline VARIABLES & $\begin{array}{l}\text { NEW FIRM } \\
\operatorname{mod.1}\end{array}$ & $\begin{array}{l}\text { NEW FIRM } \\
\text { mod. } 2\end{array}$ & $\begin{array}{l}\text { NEW FIRM } \\
\bmod 3\end{array}$ & $\begin{array}{l}\text { NEW MKT } \\
\text { mod.1a }\end{array}$ & $\begin{array}{l}\text { NEW MKT } \\
\text { mod. } 2 a\end{array}$ & $\begin{array}{l}\text { NEW MKT } \\
\text { mod. } 3 a\end{array}$ \\
\hline Innovative sales (t-1) & $\begin{array}{l}0.0518 \\
(0.0382)\end{array}$ & $\begin{array}{l}0.0925 * * \\
(0.0372)\end{array}$ & $\begin{array}{l}0.0776 * * \\
(0.0368)\end{array}$ & $\begin{array}{l}0.0343 \\
(0.0425)\end{array}$ & $\begin{array}{l}0.106 * * * \\
(0.0394)\end{array}$ & $\begin{array}{l}0.0833 * * \\
(0.0362)\end{array}$ \\
\hline Relatedness (ln) & $\begin{array}{l}2.538 * \\
(1.514)\end{array}$ & $\begin{array}{l}2.890 * * \\
(1.425)\end{array}$ & $\begin{array}{l}2.206 \\
(1.491)\end{array}$ & $\begin{array}{l}4.867 * * * \\
(1.308)\end{array}$ & $\begin{array}{l}4.941 * * * \\
(1.204)\end{array}$ & $\begin{array}{l}3.758 * * * \\
(1.233)\end{array}$ \\
\hline Relatedness $^{2}(\ln )^{2}$ & $\begin{array}{l}-0.379^{*} \\
(0.213)\end{array}$ & $\begin{array}{l}-0.399 * * \\
(0.200)\end{array}$ & $\begin{array}{l}-0.273 \\
(0.204)\end{array}$ & $\begin{array}{l}-0.751 * * * \\
(0.186)\end{array}$ & $\begin{array}{l}-0.736 * * * \\
(0.171)\end{array}$ & $\begin{array}{l}-0.529 * * * \\
(0.169)\end{array}$ \\
\hline Acquisition experience (ln) & $\begin{array}{l}-0.962 * * \\
(0.384)\end{array}$ & $\begin{array}{l}-0.722 * \\
(0.396)\end{array}$ & $\begin{array}{l}-2.712 * * \\
(1.266)\end{array}$ & $\begin{array}{l}-0.367 \\
(0.372)\end{array}$ & $\begin{array}{l}-0.123 \\
(0.362)\end{array}$ & $\begin{array}{l}-2.094 * * \\
(1.011)\end{array}$ \\
\hline Acquisition experience $^{2}(\ln )^{2}$ & $\begin{array}{l}0.363 * * * \\
(0.137)\end{array}$ & $\begin{array}{l}0.271^{*} \\
(0.142)\end{array}$ & $\begin{array}{l}0.936 * * * \\
(0.265)\end{array}$ & $\begin{array}{l}0.119 \\
(0.127)\end{array}$ & $\begin{array}{l}0.0180 \\
(0.128)\end{array}$ & $\begin{array}{l}0.725 * * * \\
(0.207)\end{array}$ \\
\hline R\&D intensity (ln) & $\begin{array}{l}0.171 * * * \\
(0.0428)\end{array}$ & $\begin{array}{l}0.599 * * * \\
(0.139)\end{array}$ & $\begin{array}{l}0.666 * * * \\
(0.142)\end{array}$ & $\begin{array}{l}0.0940^{*} \\
(0.0555)\end{array}$ & $\begin{array}{l}0.421 * * * \\
(0.119)\end{array}$ & $\begin{array}{l}0.489 * * * \\
(0.120)\end{array}$ \\
\hline Relatedness x R\&D intensity & & $\begin{array}{l}-0.276 * * * \\
(0.0596)\end{array}$ & $\begin{array}{l}-0.299 * * * \\
(0.0562)\end{array}$ & & $\begin{array}{l}-0.260 * * * \\
(0.0505)\end{array}$ & $\begin{array}{l}-0.272 * * * \\
(0.0481)\end{array}$ \\
\hline (Relatedness $\mathrm{x}$ R\&D intensity) $^{2}$ & & $\begin{array}{l}0.00501 * * * \\
(0.00113)\end{array}$ & $\begin{array}{l}0.00536 * * * \\
(0.000961)\end{array}$ & & $\begin{array}{l}0.00515 * * * \\
(0.000977)\end{array}$ & $\begin{array}{l}0.00520 * * * \\
(0.000799)\end{array}$ \\
\hline Relatedness x Acquisition experience & & & $\begin{array}{l}0.592 * \\
(0.336)\end{array}$ & & & $\begin{array}{l}0.597 * * \\
(0.275)\end{array}$ \\
\hline${\text { (Relatedness x Acquisition experience })^{2}}^{2}$ & & & $\begin{array}{l}-0.0516 * * * \\
(0.0165)\end{array}$ & & & $\begin{array}{l}-0.0549 * * * \\
(0.0141)\end{array}$ \\
\hline Target age $(\ln )$ & $\begin{array}{l}0.122 \\
(0.114)\end{array}$ & $\begin{array}{l}0.120 \\
(0.110)\end{array}$ & $\begin{array}{l}0.112 \\
(0.110)\end{array}$ & $\begin{array}{l}0.0873 \\
(0.102)\end{array}$ & $\begin{array}{l}0.0875 \\
(0.101)\end{array}$ & $\begin{array}{l}0.0299 \\
(0.100)\end{array}$ \\
\hline Target size $(\ln )$ & $\begin{array}{l}-0.0155 \\
(0.0755)\end{array}$ & $\begin{array}{l}-0.0467 \\
(0.0757)\end{array}$ & $\begin{array}{l}-0.0501 \\
(0.0753)\end{array}$ & $\begin{array}{l}0.134 * * \\
(0.0614)\end{array}$ & $\begin{array}{l}0.0566 \\
(0.0612)\end{array}$ & $\begin{array}{l}0.0545 \\
(0.0624)\end{array}$ \\
\hline Acquirer age $(\ln )$ & $\begin{array}{l}-0.134 \\
(0.111)\end{array}$ & $\begin{array}{l}-0.0826 \\
(0.108)\end{array}$ & $\begin{array}{l}-0.145 \\
(0.104)\end{array}$ & $\begin{array}{l}-0.137 \\
(0.107)\end{array}$ & $\begin{array}{l}-0.0722 \\
(0.108)\end{array}$ & $\begin{array}{l}-0.180 * \\
(0.101)\end{array}$ \\
\hline Acquirer size (ln) & $\begin{array}{l}0.745^{* * * *} \\
(0.121)\end{array}$ & $\begin{array}{l}0.577 * * * \\
(0.128)\end{array}$ & $\begin{array}{l}0.587 * * * \\
(0.125)\end{array}$ & $\begin{array}{l}0.574 * * * \\
(0.136)\end{array}$ & $\begin{array}{l}0.344 * * \\
(0.139)\end{array}$ & $\begin{array}{l}0.377 * * * \\
(0.128)\end{array}$ \\
\hline Dummies for technological regimes & yes & yes & yes & yes & yes & yes \\
\hline Time dummies (form 1997 til 2004) & yes & yes & yes & yes & yes & yes \\
\hline Constant & $\begin{array}{l}-0.695 \\
(2.602)\end{array}$ & $\begin{array}{l}-0.633 \\
(2.463)\end{array}$ & $\begin{array}{l}0.0858 \\
(2.679)\end{array}$ & $\begin{array}{l}-2.225 \\
(2.271)\end{array}$ & $\begin{array}{l}-1.221 \\
(2.084)\end{array}$ & $\begin{array}{l}0.116 \\
(2.283)\end{array}$ \\
\hline Observations & 512 & 512 & 512 & 362 & 362 & 362 \\
\hline Hansen-Sargan J statistic & 21.76 & 23.16 & 25.31 & 14.85 & 17.29 & 17.88 \\
\hline J statistics $\chi^{2}(8)$ p-value & 0.0054 & 0.0031 & 0.0014 & 0.0621 & 0.0272 & 0.0222 \\
\hline $\mathrm{R}^{2}$ & 0.208 & 0.263 & 0.303 & 0.387 & 0.442 & 0.506 \\
\hline
\end{tabular}

Note: Instrumented variable: Innovative sales ( $t-1)$. Robust standard errors in parentheses. $* * * p<0.01, * * p<0.05, * p<0.1$ 
Figure 1. Moderating effect of the acquirer's R\&D intensity (Table IV: Model 3 and 3a).

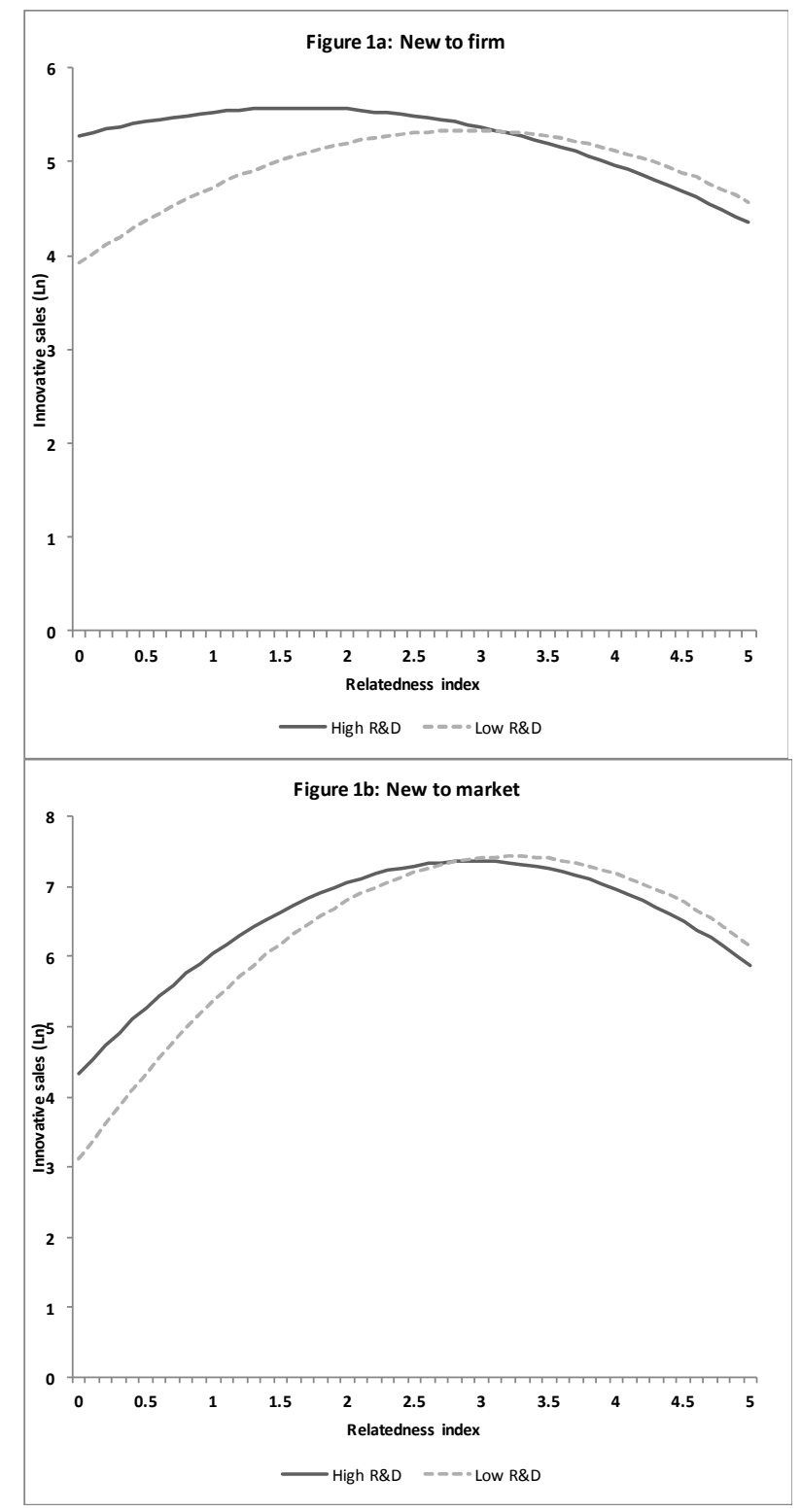

This article is protected by copyright. All rights reserved. 
Figure 2. Moderating effect of the acquirer's acquisition experience (Table IV: Model 3 and 3a).

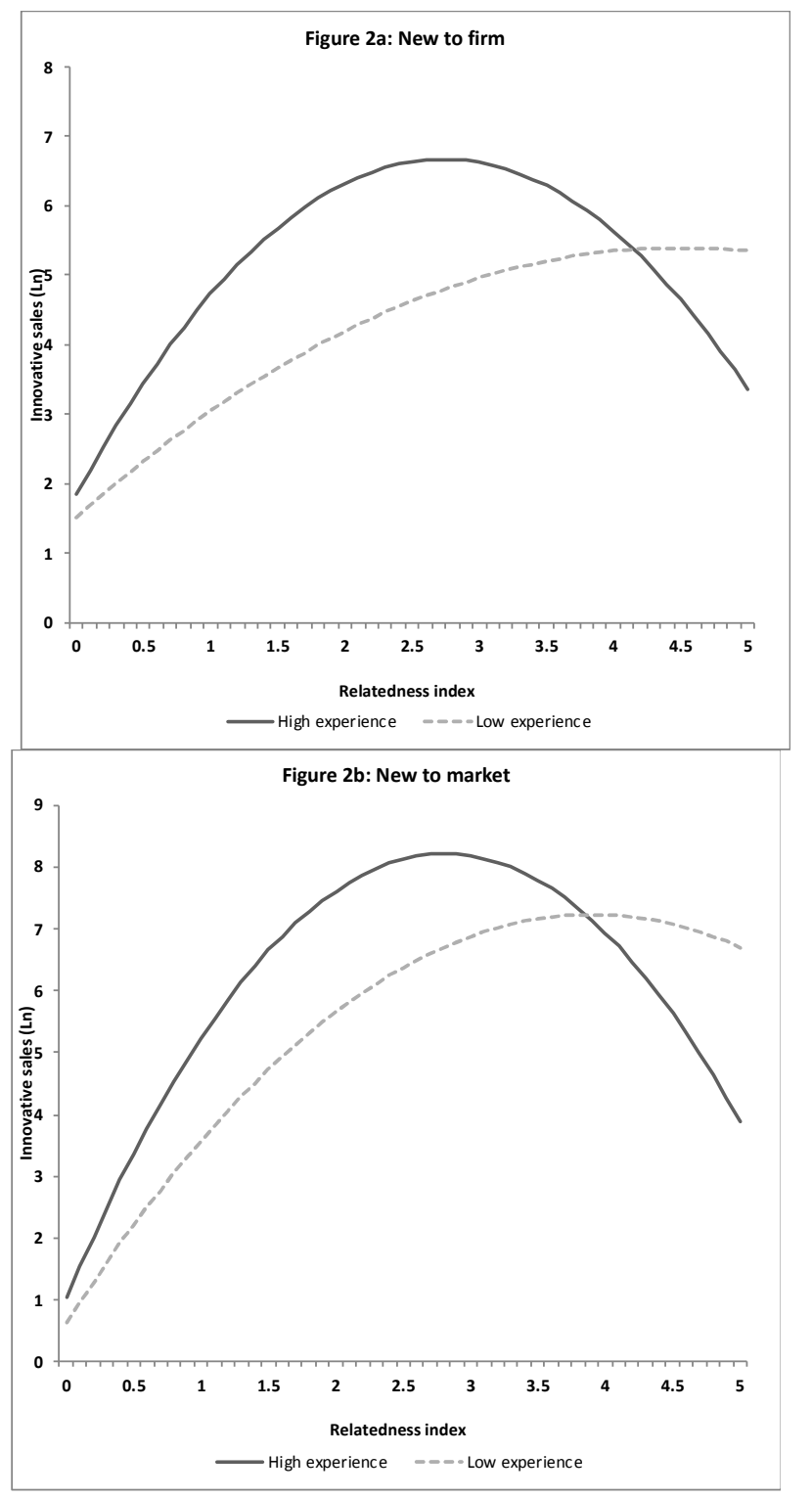

This article is protected by copyright. All rights reserved. 